\title{
Systems Pharmacological Approach of Pulsatillae Radix on Treating Crohn's Disease
}

\author{
Su Yeon Suh and Won G. An \\ Department of Pharmacology, School of Korean Medicine, Pusan National University, Yangsan, \\ Gyeongnam 50612, Republic of Korea \\ Correspondence should be addressed to Won G. An; wgan@pusan.ac.kr
}

Received 20 January 2017; Revised 28 February 2017; Accepted 1 March 2017; Published 1 June 2017

Academic Editor: Jae Youl Cho

Copyright (C) $2017 \mathrm{Su}$ Yeon Suh and Won G. An. This is an open access article distributed under the Creative Commons Attribution License, which permits unrestricted use, distribution, and reproduction in any medium, provided the original work is properly cited.

In East Asian traditional medicine, Pulsatillae Radix (PR) is widely used to treat amoebic dysentery and renowned for its antiinflammatory effects. This study aimed to confirm evidence regarding the potential therapeutic effect of PR on Crohn's disease using a system network level based in silico approach. Study results showed that the compounds in PR are highly connected to Crohn's disease related pathways, biological processes, and organs, and these findings were confirmed by compound-target network, targetpathway network, and gene ontology analysis. Most compounds in PR have been reported to possess anti-inflammatory, anticancer, and antioxidant effects, and we found that these compounds interact with multiple targets in a synergetic way. Furthermore, the mRNA expressions of genes targeted by PR are elevated significantly in immunity-related organ tissues, small intestine, and colon. Our results suggest that the anti-inflammatory and repair and immune system enhancing effects of PR might have therapeutic impact on Crohn's disease.

\section{Introduction}

Inflammatory bowel disease (IBD) may be categorized clinically as Crohn's disease or ulcerative colitis [1]. Crohn's disease usually causes a variety of systemic symptoms, which include chronic inflammation of the bowel [2]. Although any part of the digestive tract from mouth to anus may be affected, usually the small intestine (ileum) and the large intestine (colon) are involved; ileocolic Crohn's accounts for $50 \%$ of cases, ileal Crohn's for 30\%, and colic Crohn's for $20 \%$ of cases [3]. Symptoms vary though its common manifestations include persistent diarrhea, rectal bleeding, abdominal cramps, and pain, though fever, extreme fatigue, and weight loss are also common $[1,2,4]$. Constipation is also a frequent symptom and can lead to bowel obstruction and, thus, increase the risk of bowel cancer. Complications involving other than the gastrointestinal (GI) tract include anemia, arthritis, liver disease, eye inflammation, and skin rashes $[2,4]$.

According to a statistical report issued by the Health Insurance Review and Assessment Service in Korea in 2016, the number of Crohn's disease patients increased from 13,920 in 2011 to 18,332 in 2015, an average annual increase of 7.1\%. Furthermore, over the same period, total medical cost has increased by $19.4 \%$ annually, and more than half of patients are in 20 s or 30 s. A systematic review about the economic and quality-of-life burden of Crohn's disease reported that, in the USA, Germany, France, UK, Italy, and Spain, in all countries combined, Crohn's medical costs totaled $€ 30$ billion annually and that patient quality of life was substantially diminished by the physical, emotional, and social effects of the disease [5].

Although Crohn's disease is a global health problem [5], its pathology remains poorly understood $[1,6]$. Nevertheless, it has been established that its etiology is associated with complex interactions between environmental, immune, microbial, and genetic factors $[4,7]$, though a number of authors have suggested that the primary defect in Crohn's disease is one of relative immunodeficiency $[6,8,9]$.

A systematic review of publications from 1947 to 2013 involving controlled studies of herbal therapies in IBD indicated that at least 50 percent of IBD patients used some form of complementary and alternative medicine (CAM), since most herbal therapies had been reported to have antiinflammatory effects and plausible action mechanisms in 


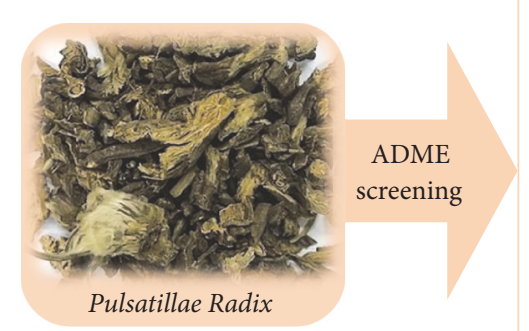

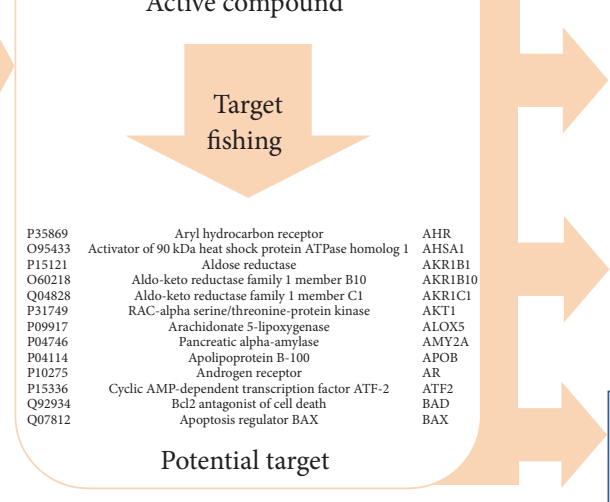

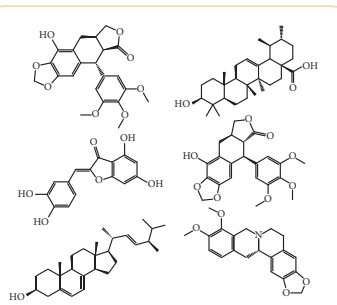

Active compound
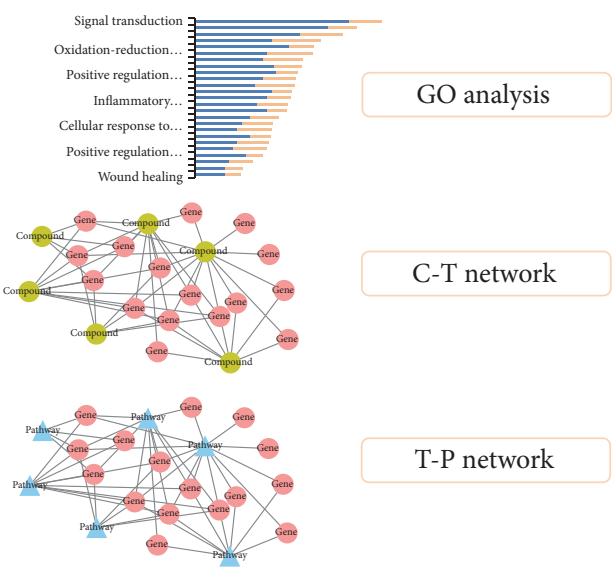

T-P network

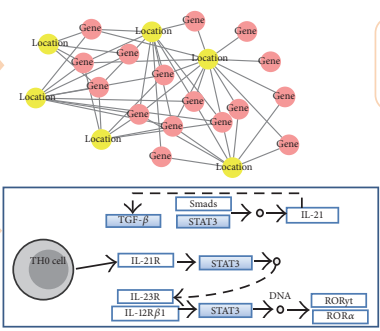

Target organ location

Network pathway

FIGURE 1: Workflow: network analysis, relevant organ location network analysis, gene ontology, and pathway analysis were performed on active compounds identified in Pulsatillae Radix (PR) by screening and target fishing.

IBD with minimal adverse effects [10]. Moreover, herbal medicines are being increasingly used and requested by IBD patients not only in Asia, but also in Western countries [11].

Of the anti-inflammatory herbal medicines, Pulsatillae Radix (Baekduong, PR) is worth considering as a potential treatment for Crohn's disease as it was widely used in traditional medicine to treat amoebic dysentery and has also been demonstrated scientifically to have anti-inflammatory effects experimentally $[12,13]$. PR is traditional Korean herbal medicine prepared from the roots of Pulsatilla koreana Nakai and contains several phytochemicals, including anemonin, hederagenin, oleanolic acid, and deoxypodophyllotoxin [14, 15]. Some experimental study results have shown that PR has various biological activities. For instance, aqueous and ethanol extracts of PR have been reported to demonstrate anticancer effects in anaplastic thyroid cancer [16], methanol extract of PR was found to have anti-inflammatory effects in lipopolysaccharide (LPS) exposed rats [17], and PR has also been reported to inhibit adipocyte differentiation and to suppress adipogenesis [13].

According to the meridian tropism theory of traditional medicine, the effects of $P R$ reach to the stomach meridian and the large intestine meridian, which is in accord with the organs commonly affected by Crohn's disease. In terms of the selection of traditional medication, meridian tropism theory plays an important role, as it is one of the core principles of traditional medicine [18]. Based on meridian tropism theory, each herbal medicine possesses different affinities for certain organs and meridians of the body [19].

In the present study, we sought to confirm the therapeutic effects of PR in Crohn's disease using system level analysis and a network based in silico approach. A schematic of the network pharmacological study is summarized in Figure 1.

\section{Material and Methods}

2.1. Identification of Active Compounds. According to the Traditional Chinese Medicine Systems Pharmacology (TCMSP, http://ibts.hkbu.edu.hk/LSP/tcmsp.php) database (a free phytochemical database of herbal medicine), PR contains 57 identified compounds. Parameters related to absorption, distribution, metabolism, and excretion (ADME), namely, human drug-likeness (DL) [20], oral bioavailability (OB) [21], and Caco-2 permeability (Caco-2) [22], were employed to filter out potential active compounds.

2.1.1. Drug-Likeness Evaluation. DL helps filter out "druglike" compounds in oriental herbs, as DL represents a qualitative concept for valuations based on how "druglike" prospective compound is [23]. Accordingly, a high DL may lead to a greater possibility of therapeutic success, and compounds with a higher DL value are more likely to possess certain biological properties [24]. Calculations of DL in the TCMSP database are based on the Tanimoto coefficient formula [25] as follows:

$$
F(A, B)=\frac{A \times B}{A^{2}+B^{2}-A \times B},
$$

where $A$ represents the molecular parameters of herbal compounds and $B$ is the average molecular parameter of all compounds in the DrugBank database (http://www.drugbank.ca/) 
[26]. In the present study, we excluded compounds with a DL value of $<0.18$.

2.1.2. Oral Bioavailability $(\mathrm{OB})$ Prediction. Oral bioavailability $(\mathrm{OB})$ is defined as the absorption ratio of an active compound into the systemic circulation, which represents convergence of the ADME process [21]. OB values are dependent on drug dissolution in the gastrointestinal (GI) tract, intestinal and hepatic first-pass metabolisms, and intestinal membrane permeation, and, thus, $\mathrm{OB}$ is considered a major pharmacokinetic parameter for drug evaluations [24]. In this study, the OB threshold was set as $\geq 15 \%$.

2.1.3. Caco-2 Permeability Screening. Caco-2 permeability is used to predict the absorption of an orally administered drug [22]. Surface absorptivity of the small intestine is maximized by villi and microvilli; for this reason, orally administered drugs are mostly absorbed in the small intestine [27]. Moreover, the movement of orally administered drugs across the intestinal epithelial barrier determines the rate and extent of human absorption and ultimately affects drug bioavailability [28]. In the present study, compounds with OB, DL, and Caco- 2 values of $>15 \%,>0.18$, and $>-0.4$, respectively, were regarded as active and subjected to analysis. In addition, we included some compounds with lower ADME profile than above thresholds, for the reason that those were reported to possess anti-inflammatory, antioxidant, anticancer, and antibacterial effects. This study was about only one single herb, and for this reason we did not use a high threshold of ADME profile to filter potential active compounds. Instead, we lowered the standard of $\mathrm{OB}$ in order to analyze the most potential targets of PR.

2.2. Target Fishing. Molecular targets of filtered potential active compounds were found in the TCMSP [29], Similarity Ensemble Approach (SEA, http://sea.bkslab.org), and the Binding Database (http://www.bindingdb.org). In addition, filtered compound-target interaction profile mapping was performed using the UniProt database (http://www.uniprot .org/) [30].

2.3. Gene Ontology (GO) Analysis. Biological process (BP) of gene ontology $(\mathrm{GO})$ analysis was employed to determine the biological properties of target genes [31]. GO annotation provides statistical analyses on gene function information. In this research, GO BP terms with $P$ values $<0.01$ were employed and the data was collected using the DAVID 6.8 Gene Functional Classification Tool (http://david.abcc.ncifcrf.gov/).

2.4. Network Construction and Analysis. In order to understand the multiscale interactions between the active compounds of PR and targets, two types of networks were built: (1) a compound-target network (C-T network), in which nodes represented either compounds or target proteins, and edges indicated compound-target connections; and (2) a target-pathway network (T-P network), which was used to extract pathways from the KEGG database (http://www.genome.jp/kegg/) and to filter out terms highly associated with Crohn's disease and $P$ values of $<0.01$. Related targets were mapped onto relevant pathways to produce the T-P network. Both networks were generated in Cytoscape 3.4.0, an open-source biological network visualization and data integration software package [32].

2.5. Target Organ Location Network. Tissue-specific patterns of mRNA expression can indicate important associations with particular biological events or gene functions [33]. Thus, to explore the beneficial effects of PR on Crohn's disease, it was important to determine the tissue mRNA expression profiles of target proteins at the organ level [34]. The target organ location network was used with the Dataset: GeneAtlas U133A, gcrma (http://biogps.org). The BioGPS database provides expression data acquired by direct measurements of gene expressions by microarrays analysis [35]. First, the mRNA expression patterns of each target gene in 84 parts of organ tissues were obtained. Second, average values were calculated for each gene. Third, above average mRNA expressions in relevant organ tissues were extracted and arranged by frequency. Finally, a target organ location network was constructed using Cytoscape 3.4.0 and organspecific, Crohn's disease related, gene overexpression data.

2.6. GEO2R Analysis. Using Gene Expression Omnibus (GEO, https://www.ncbi.nlm.nih.gov/geo), we compared mRNA expression pattern of normal groups and Crohn's disease groups. GEOquery and limma R packages of GEO2R tool were employed to identify highly expressed genes.

2.7. Network Pathway. In order to elucidate the action mechanisms of PR in Crohn's disease, filtered target proteins were input into the pathway map of inflammatory bowel disease acquired from the Kyoto Encyclopedia of Genes and Genomes (KEGG, http://www.kegg.jp/) database.

\section{Results}

3.1. Identification of Active Compounds. Of the 57 compounds (as shown in Supplementary Table S1 in Supplementary Material available online at https://doi.org/10.1155/2017/4198035) in PR acquired from the TCMSP, excluding compounds with no target information, 19 compounds with a known target met the criteria $\mathrm{OB} \geq 15 \%$, Caco- $2 \geq-0.4$, and $\mathrm{DL} \geq 0.18$. Additionally 13 compounds reported to have anti-inflammatory, antioxidant, anticancer, and antibacterial effects were added, and finally 32 compounds were analyzed (as shown in Table 1).

A number of these 32 compounds have been shown experimentally to have various biological activities. For example, antioxidative effect of cernuoside $(\mathrm{C} 12 ; \mathrm{DL}=0.79$, $\mathrm{OB}=2.69$, Caco- $2=-1.51)$ was experimentally identified [36]. Pinoresinol (C23; DL $=0.52, \mathrm{OB}=4.25$, Caco-2 $=$ 0.52 ) was reported to have anti-inflammatory properties [37]. $\beta$-Sitosterol $(\mathrm{C} 32 ; \mathrm{DL}=0.71, \mathrm{OB}=5.84, \mathrm{Caco}-2=1.42)$ and campesterol $(\mathrm{C} 23 ; \mathrm{DL}=0.72, \mathrm{OB}=5.57, \mathrm{Caco}-2=$ 1.6) were reported to have the protecting effect by natural and synthetic antioxidants during heating [38]. Antiallergic 
TABLE 1: 32 potential active compounds of Pulsatillae Radix.

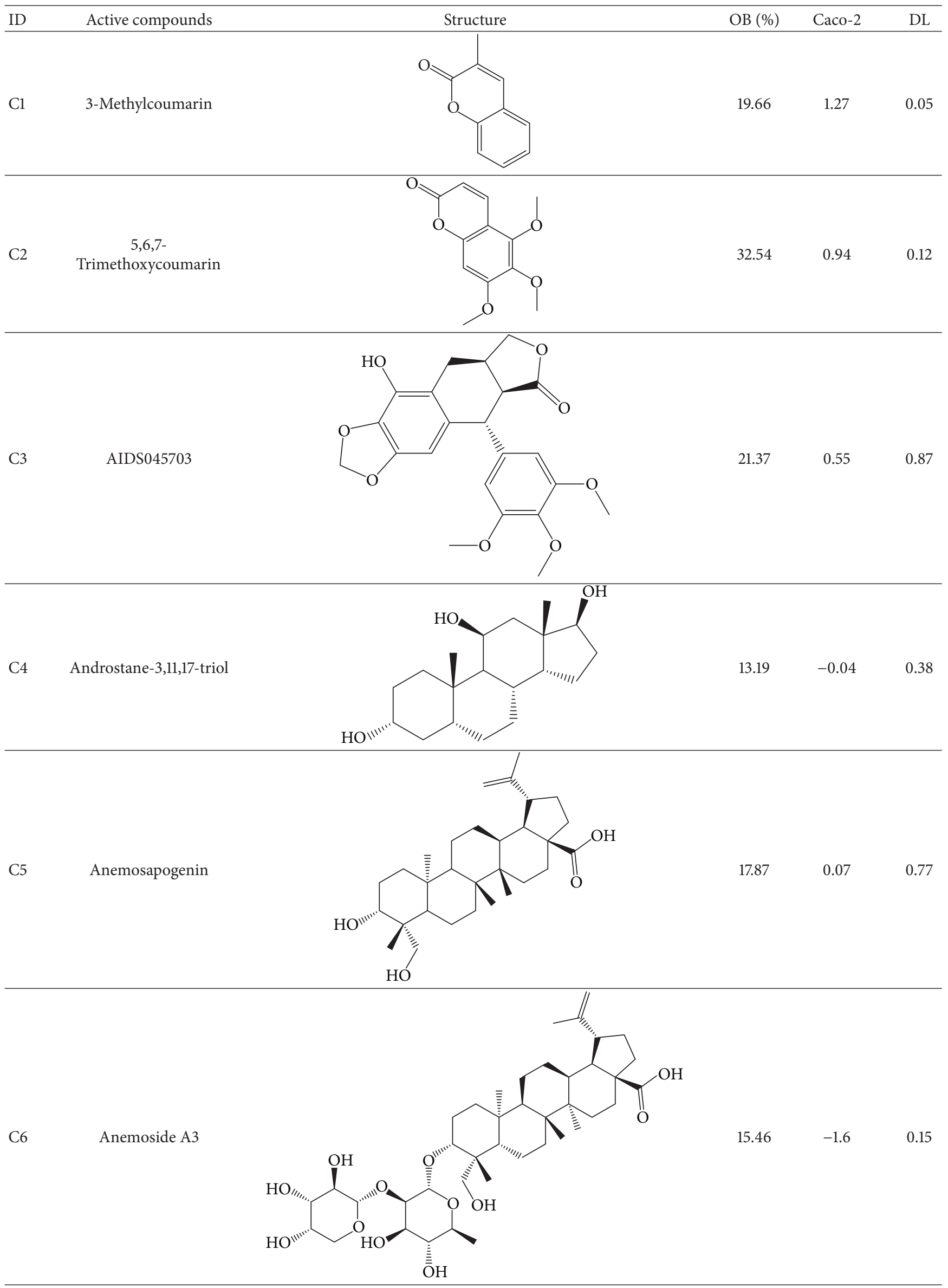


TABle 1: Continued.

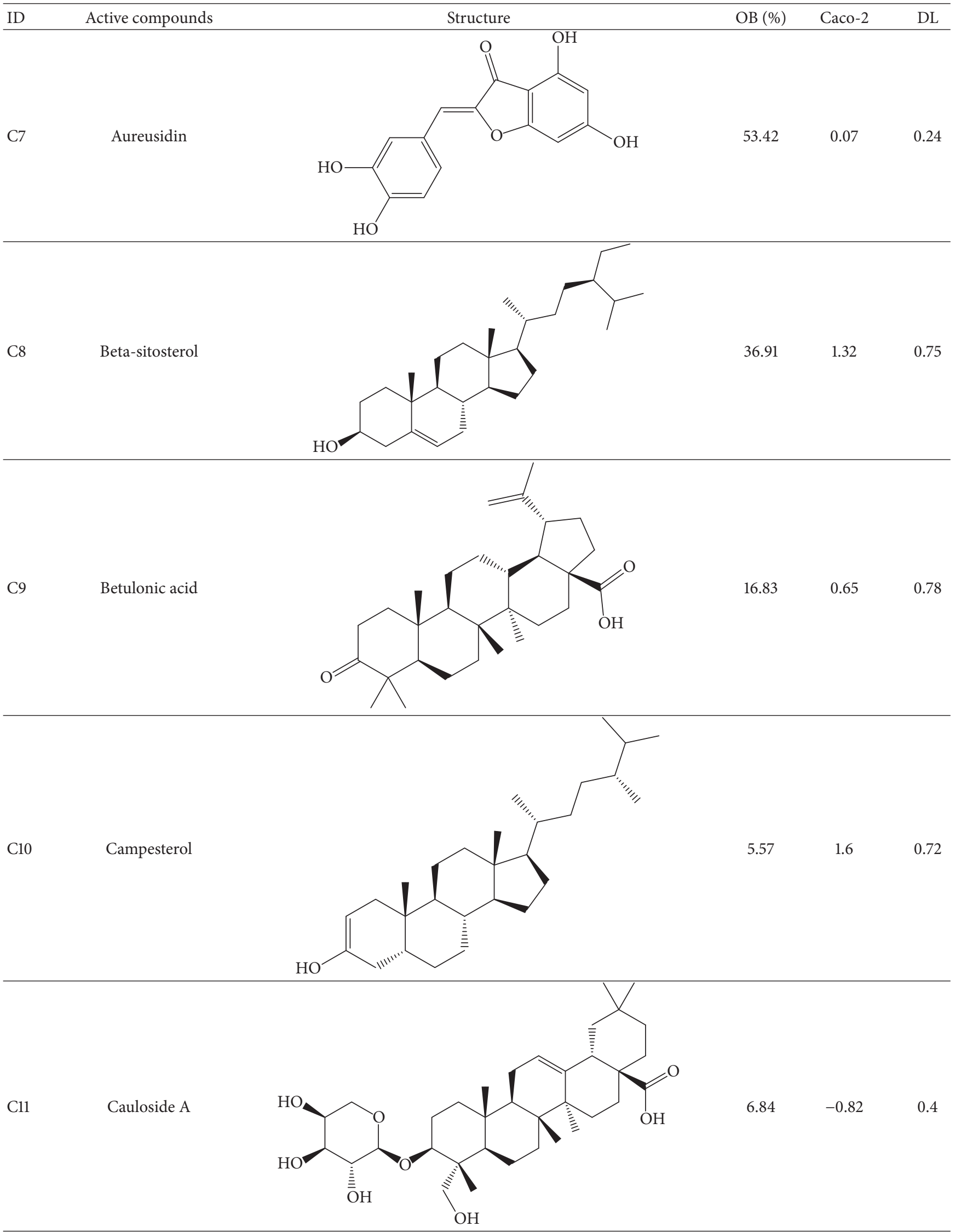


TABLE 1: Continued.

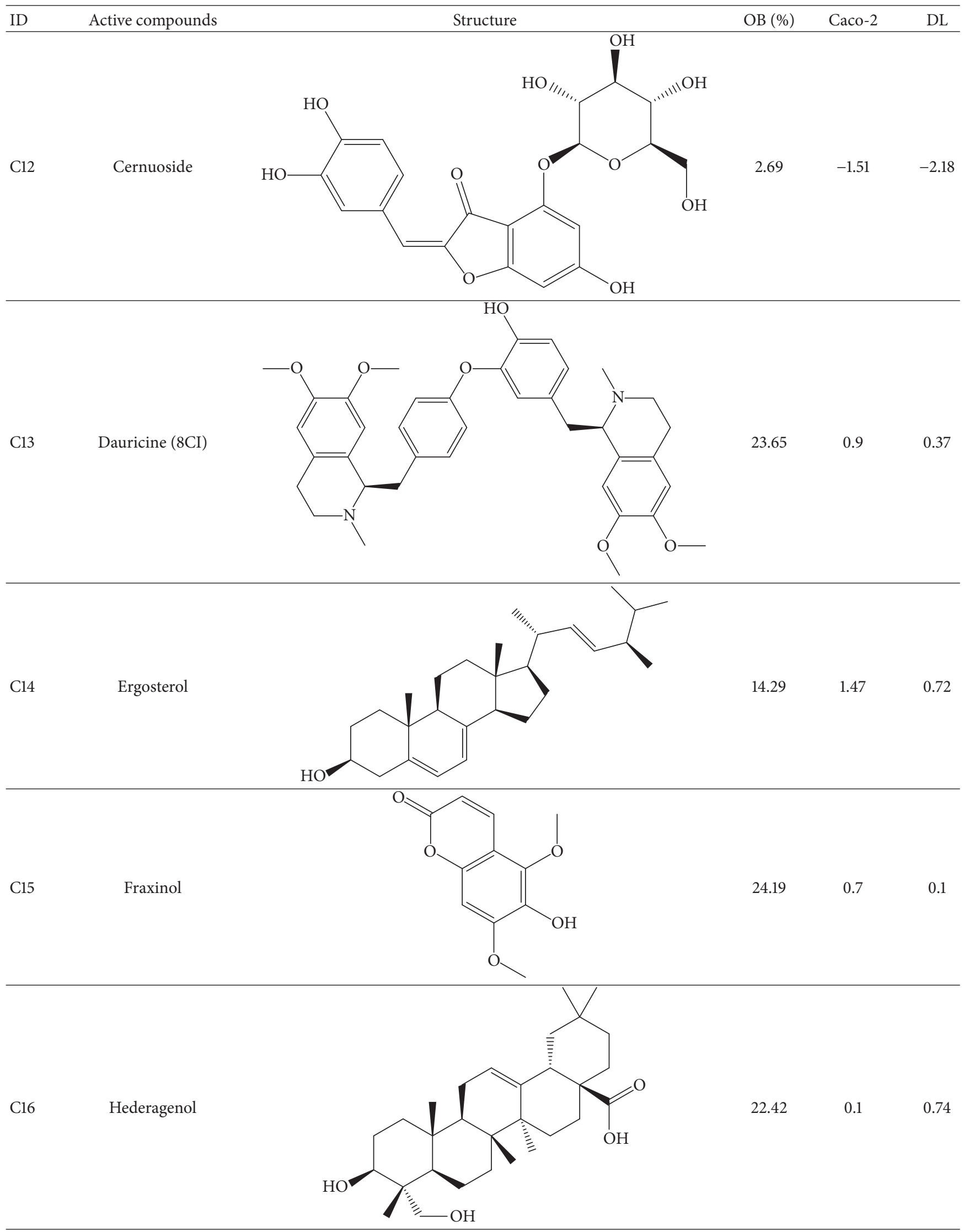


TABLE 1: Continued.

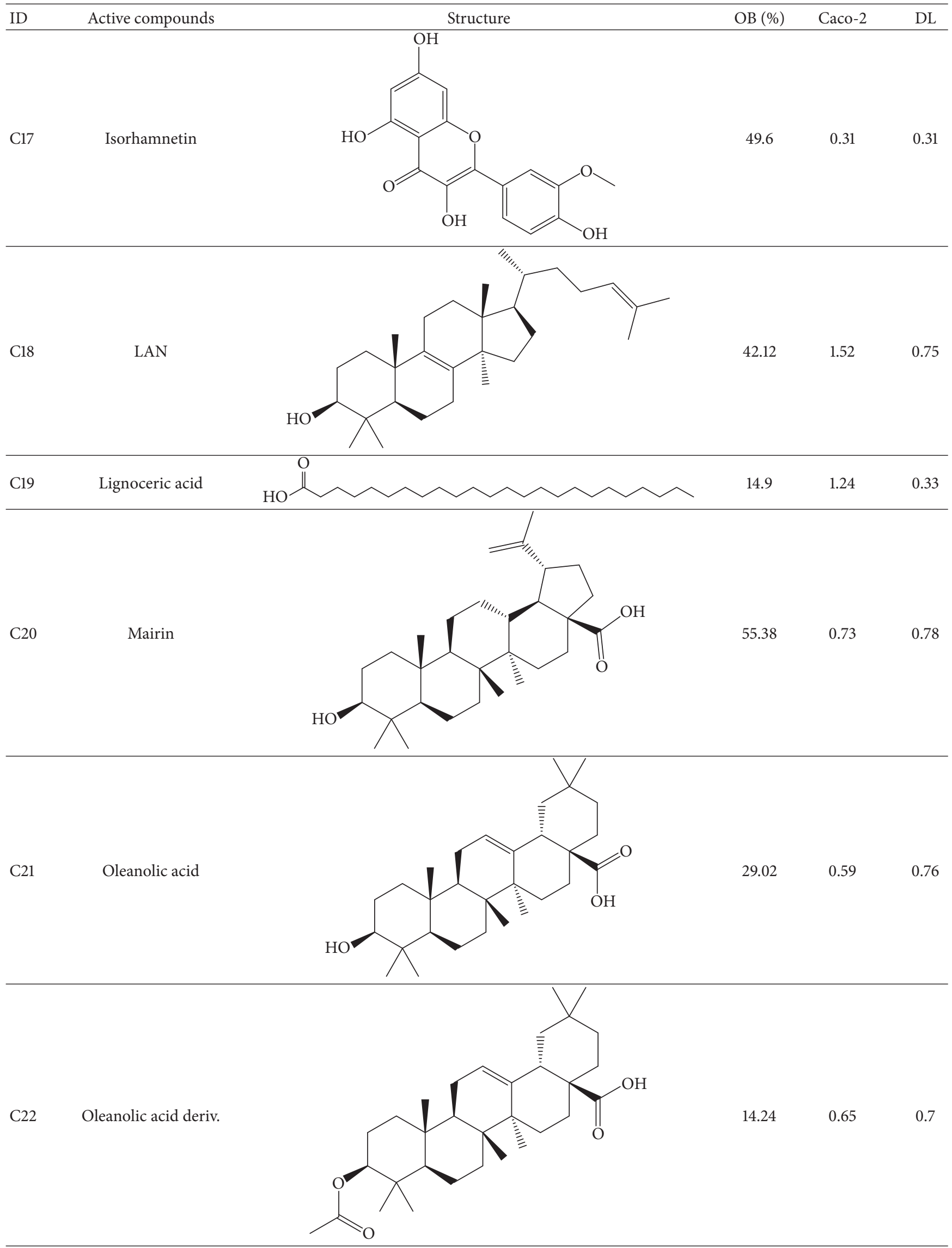


TABle 1: Continued.

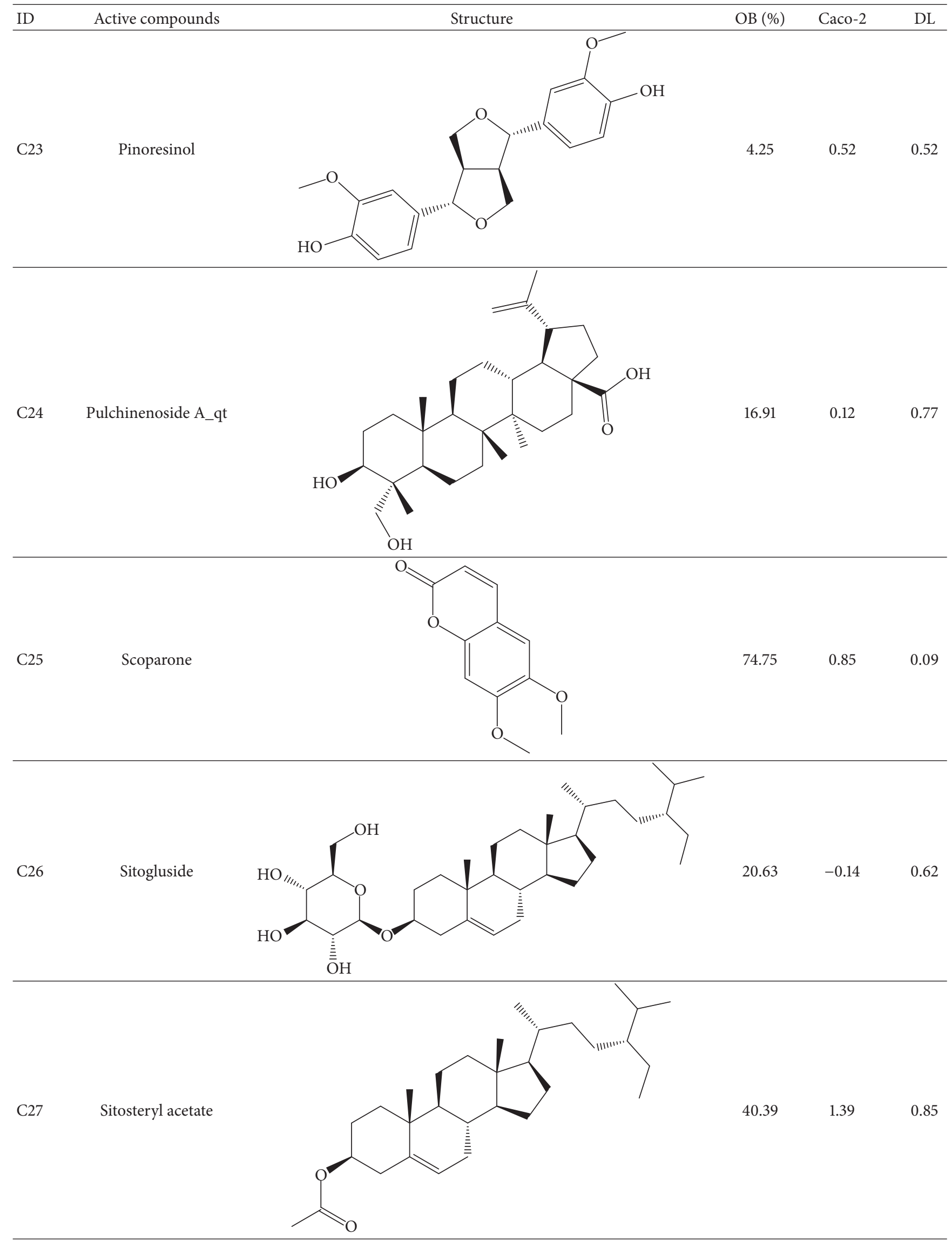


TABle 1: Continued.

\begin{tabular}{|c|c|c|c|c|c|}
\hline ID & Active compounds & Structure & OB (\%) & Caco-2 & $\mathrm{DL}$ \\
\hline $\mathrm{C} 28$ & Stigmasterol & & 43.83 & 1.44 & 0.76 \\
\hline $\mathrm{C} 29$ & Tricosanoic acid & & 15.29 & 1.18 & 0.3 \\
\hline $\mathrm{C} 30$ & Ursolic acid & & 16.77 & 0.67 & 0.75 \\
\hline C31 & ZINC01615307 & & 56.38 & 0.53 & 0.87 \\
\hline $\mathrm{C} 32$ & $\beta$-Sitosterol & & 5.84 & 1.42 & 0.71 \\
\hline
\end{tabular}

effects of scoparone $(\mathrm{C} 25 ; \mathrm{DL}=0.09, \mathrm{OB}=74.75$, Caco$2=0.85$ ) was experimentally demonstrated in rat model, which attenuates IgE-mediated allergic response in mast cells [39]. Aureusidin (C7; DL $=0.24, \mathrm{OB}=53.42$, Caco- $2=$ 0.07 ) was reported to have marked antioxidant activity and to be useful for the treatment of several diseases [40, 41], and anemosapogenin $(\mathrm{C} 5 ; \mathrm{DL}=0.77, \mathrm{OB}=17.87$, Caco-2 $=0.07)$ has antitumor effects $[42,43]$. Betulonic acid (C9; $\mathrm{DL}=0.78, \mathrm{OB}=16.83$, Caco- $2=0.65)$ possesses various medical effects, such as antiviral (HIV-1), anticancer, and immunomodulatory activities [44]. Cauloside (C11; DL = $0.4, \mathrm{OB}=6.84, \mathrm{Caco}-2=-0.82$ ) from blue cohosh was 


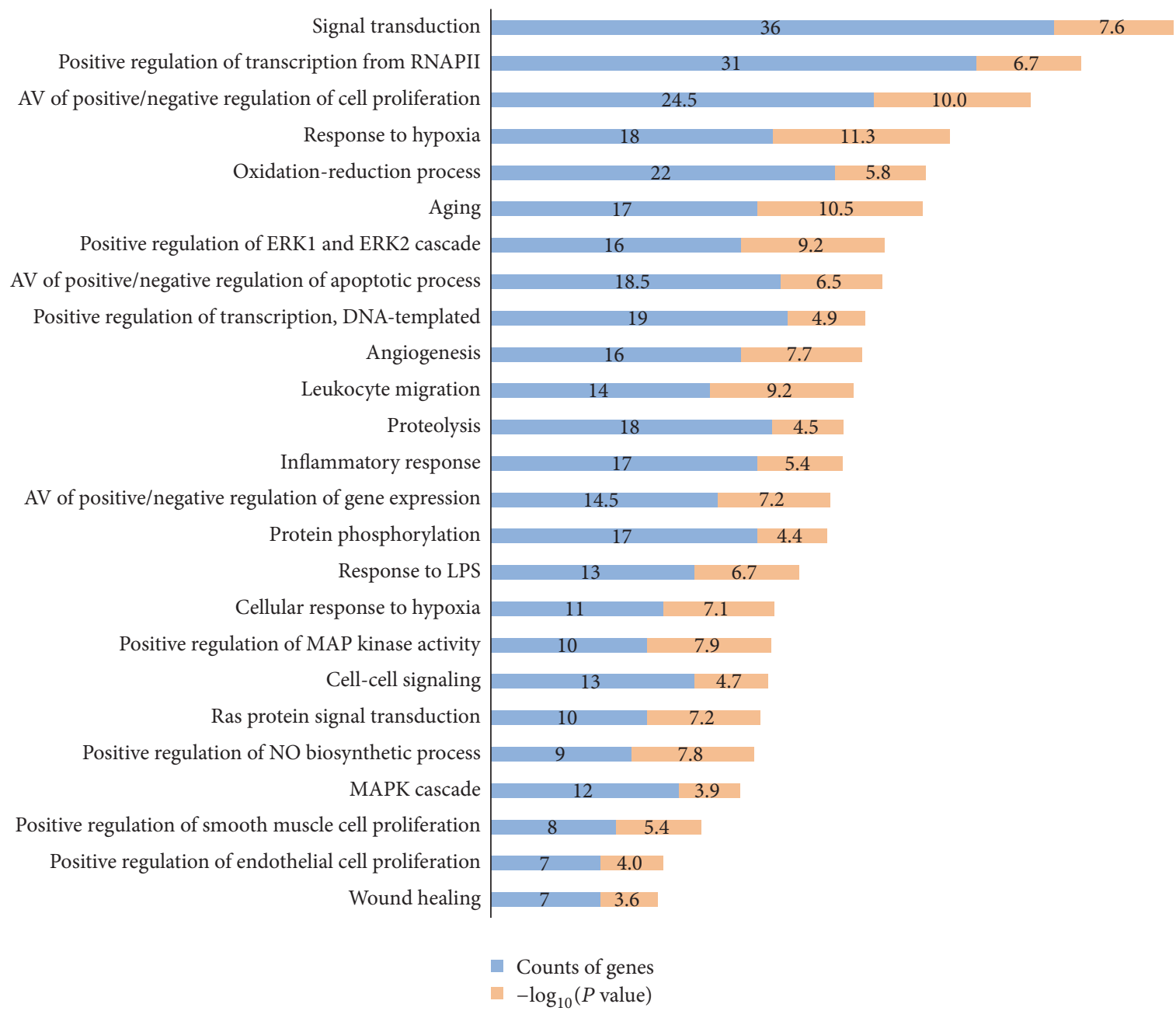

FIGURE 2: GO analysis: 25 biological process (BP) of gene ontology (GO) terms sorted by $P$ value $<0.01$. Counts of genes and $P$ value related to each BP terms are shown. The $y$-axis represents BP terms for the target genes, and the $x$-axis shows counts of genes and $-\log _{10}(P$ value).

reported to inhibit proinflammatory cytokine induction by LPS [45]. Dauricine (C13; DL $=0.9, \mathrm{OB}=23.65$, Caco$2=0.37$ ) from Asiatic moonseed was reported to have significant antibacterial and anti-inflammatory effects [46], and ergosterol $(\mathrm{C} 14 ; \mathrm{DL}=0.72, \mathrm{OB}=14.29$, Caco-2 $=1.47)$ [47] from the mushroom and isorhamnetin $(\mathrm{C} 17 ; \mathrm{DL}=0.31$, $\mathrm{OB}=49.6$, Caco-2 = 0.31) [48] were both found to have anti-inflammatory effects. Furthermore, oleanolic acid (C21; $\mathrm{DL}=0.76, \mathrm{OB}=29.02$, Caco-2 $=0.59)$ and ursolic acids $(\mathrm{C} 30 ; \mathrm{DL}=0.75, \mathrm{OB}=16.77, \mathrm{Caco}-2=0.67)$ have been reported to have antioxidative and anti-inflammatory effect $[49,50]$. As mentioned above, PR contains many compounds, which are ubiquitous in plants, herbs, and fruits, with antiinflammatory, anticancer, and antioxidative effects.

3.2. Target Fishing. These 32 identified active compounds interact with 182 target proteins (Table 2); that is, on average, they interact with 5.7 target genes, which does much to explain the polypharmacological and synergistic effects of PR on multiple targets [51].
3.3. GO Analysis. For the filtered 182 target genes, 469 biological process terms with $P$ values of $<0.01$ were sorted using the functional annotation chart of the DAVID 6.8 Gene Functional Classification Tool and $P$ values were adjusted using Benjamini-Hochberg method. This process resulted in the identification of 25 biological process terms. GO analysis showed that the 182 genes were highly related to inflammation, proliferation, oxidation reduction, and the regulations of apoptosis and signal transduction (Figure 2).

In detail, phosphatidylinositol-4, 5-bisphosphate 3kinase catalytic subunit, gamma isoform (PIK3CG), interleukin-6 (IL6), tumor necrosis factor (TNF), C-C motif chemokine 2 (CCL2), prostaglandin E2 receptor EP3 subtype (PTGER3), oxidized low-density lipoprotein receptor 1 (OLR1), prostaglandin G/H synthase 2 (PTGS2), and others are related to "inflammatory response."

Androgen receptor (AR), interleukin-6 (IL6), heparinbinding growth factor 2 (FGF2), GTPase HRas (HRAS), hematopoietic cell protein-tyrosine phosphatase (PTPN6), and signal transducer and activator of transcription 3 
TABLE 2: Related targets of Pulsatillae Radix.

\begin{tabular}{|c|c|c|}
\hline UniProt ID & Target & Gene name \\
\hline Q92887 & Canalicular multispecific organic anion transporter 1 & $\mathrm{ABCC} 2$ \\
\hline P12821 & Angiotensin-converting enzyme & $\mathrm{ACE}$ \\
\hline P22303 & Acetylcholinesterase & $\mathrm{ACHE}$ \\
\hline P24666 & Low molecular weight phosphotyrosine protein phosphatase & $\mathrm{ACP} 1$ \\
\hline P00326 & Alcohol dehydrogenase $1 \mathrm{C}$ & $\mathrm{ADH} 1 \mathrm{C}$ \\
\hline P35348 & Alpha-1A adrenergic receptor & ADRA1A \\
\hline P35368 & Alpha-1B adrenergic receptor & ADRA1B \\
\hline P25100 & Alpha-1D adrenergic receptor & ADRA1D \\
\hline P08913 & Alpha-2A adrenergic receptor & ADRA2A \\
\hline P18825 & Alpha-2C adrenergic receptor & ADRA2C \\
\hline P08588 & Beta-1 adrenergic receptor & ADRB1 \\
\hline P07550 & Beta-2 adrenergic receptor & $\mathrm{ADRB} 2$ \\
\hline P15121 & Aldose reductase & AKR1B1 \\
\hline O60218 & Aldo-keto reductase family 1 member B10 & AKR1B10 \\
\hline P09917 & Arachidonate 5-lipoxygenase & ALOX5 \\
\hline P09923 & Intestinal-type alkaline phosphatase & ALPI \\
\hline P04746 & Pancreatic alpha-amylase & AMY2A \\
\hline P10275 & Androgen receptor & $\mathrm{AR}$ \\
\hline P15336 & Cyclic AMP-dependent transcription factor ATF-2 & ATF2 \\
\hline P05023 & Sodium/potassium-transporting ATPase subunit alpha-1 & ATP1A1 \\
\hline P15291 & Beta-1,4-galactosyltransferase 1 & B4GALT1 \\
\hline Q07812 & Apoptosis regulator $\mathrm{BAX}$ & BAX \\
\hline P10415 & Apoptosis regulator Bcl-2 & BCL2 \\
\hline Q07817 & Bcl-2-like protein 1 & BCL2L1 \\
\hline O15392 & Baculoviral IAP repeat-containing protein 5 & BIRC5 \\
\hline O43570 & Carbonic anhydrase 12 & CA12 \\
\hline Q8N1Q1 & Carbonic anhydrase 13 & CA13 \\
\hline P00918 & Carbonic anhydrase II & CA2 \\
\hline P22748 & Carbonic anhydrase IV & CA4 \\
\hline P35218 & Carbonic anhydrase $5 \mathrm{~A}$, mitochondrial & CA5A \\
\hline Q16790 & Carbonic anhydrase VI & CA9 \\
\hline P62158 & Calmodulin & CALM1 \\
\hline P29466 & Caspase-1 & CASP1 \\
\hline P42574 & Caspase-3 & CASP3 \\
\hline Q14790 & Caspase- 8 & CASP8 \\
\hline P55211 & Caspase-9 & CASP9 \\
\hline P13500 & $\mathrm{C}-\mathrm{C}$ motif chemokine 2 & CCL2 \\
\hline P20248 & Cyclin-A2 & CCNA2 \\
\hline P24385 & G1/S-specific cyclin-D1 & CCND1 \\
\hline P30279 & G1/S-specific cyclin-D2 & CCND2 \\
\hline P60033 & CD81 antigen & CD81 \\
\hline P24941 & Cell division protein kinase 2 & CDK2 \\
\hline P11802 & Cell division protein kinase 4 & $\mathrm{CDK} 4$ \\
\hline Q00534 & Cell division protein kinase 6 & CDK6 \\
\hline P38936 & Cyclin-dependent kinase inhibitor 1 & CDKN1A \\
\hline O14757 & Serine/threonine-protein kinase Chk1 & CHEK1 \\
\hline P11229 & Muscarinic acetylcholine receptor M1 & CHRM1 \\
\hline P08172 & Muscarinic acetylcholine receptor M2 & CHRM2 \\
\hline P20309 & Muscarinic acetylcholine receptor M3 & CHRM3 \\
\hline P08173 & Muscarinic acetylcholine receptor M4 & CHRM4 \\
\hline Q15822 & Neuronal acetylcholine receptor subunit alpha- 2 & CHRNA2 \\
\hline P36544 & Neuronal acetylcholine receptor protein, alpha-7 chain & CHRNA7 \\
\hline
\end{tabular}


TABLe 2: Continued.

\begin{tabular}{|c|c|c|}
\hline UniProt ID & Target & Gene name \\
\hline O15111 & NF-kappa-B inhibitor alpha & CHUK \\
\hline P16220 & Cyclic AMP-responsive element-binding protein 1 & CREB1 \\
\hline P15509 & Granulocyte-macrophage colony-stimulating factor & CSF2RA \\
\hline P17538 & Chymotrypsinogen B & CTRB1 \\
\hline P07858 & Cathepsin B & CTSB \\
\hline $\mathrm{P} 10145$ & Interleukin-8 & CXCL8 \\
\hline Q16850 & Lanosterol 14-alpha demethylase & CYP51A1 \\
\hline Q9UBM7 & 7-Dehydrocholesterol reductase & DHCR7 \\
\hline P27487 & Dipeptidyl peptidase IV & DPP4 \\
\hline P21728 & Dopamine D1 receptor & DRD1 \\
\hline Q9NRD8 & Dual oxidase 2 & DUOX2 \\
\hline Q6UWV6 & Intestinal alkaline sphingomyelinase & ENPP7 \\
\hline Q99814 & Endothelial PAS domain-containing protein 1 & EPAS1 \\
\hline P03372 & Estrogen receptor & ESR1 \\
\hline Q92731 & Estrogen receptor beta & ESR2 \\
\hline P00742 & Coagulation factor $\mathrm{Xa}$ & F10 \\
\hline P00734 & Thrombin & $\mathrm{F} 2$ \\
\hline P08709 & Coagulation factor VII & F7 \\
\hline P48023 & Tumor necrosis factor ligand superfamily member 6 & FASLG \\
\hline P49327 & Fatty acid synthase & FASN \\
\hline P05230 & Fibroblast growth factor 1 & FGF1 \\
\hline P09038 & Heparin-binding growth factor 2 & FGF2 \\
\hline P01100 & Proto-oncogene c-Fos & FOS \\
\hline P14867 & Gamma-aminobutyric acid receptor subunit alpha-1 & GABRA1 \\
\hline P47869 & Gamma-aminobutyric-acid receptor alpha-2 subunit & GABRA2 \\
\hline P34903 & Gamma-aminobutyric-acid receptor alpha-3 subunit & GABRA3 \\
\hline P31644 & Gamma-aminobutyric-acid receptor alpha- 5 subunit & GABRA5 \\
\hline P17677 & Neuromodulin & GAP43 \\
\hline Q8TDU6 & G-protein coupled bile acid receptor 1 & GPBAR1 \\
\hline P42262 & Glutamate receptor 2 & GRIA2 \\
\hline P49841 & Glycogen synthase kinase- 3 beta & GSK3B \\
\hline Q9UII4 & Probable E3 ubiquitin-protein ligase HERC5 & HERC5 \\
\hline P09601 & Heme oxygenase 1 & HMOX1 \\
\hline P01112 & GTPase HRas & HRAS \\
\hline P28845 & Corticosteroid 11-beta-dehydrogenase isozyme 1 & HSD11B1 \\
\hline P80365 & Corticosteroid 11-beta-dehydrogenase isozyme 2 & HSD11B2 \\
\hline P08238 & Heat shock protein HSP 90 & HSP90AB1 \\
\hline P28223 & 5-Hydroxytryptamine $2 \mathrm{~A}$ receptor & HTR2A \\
\hline P46098 & 5-Hydroxytryptamine receptor $3 \mathrm{~A}$ & HTR3A \\
\hline P05362 & Intercellular adhesion molecule 1 & ICAM1 \\
\hline P01857 & Ig gamma-1 chain $\mathrm{C}$ region & IGHG1 \\
\hline P01584 & Interleukin-1 beta & IL1B \\
\hline P60568 & Interleukin-2 & IL2 \\
\hline P05231 & Interleukin-6 & IL6 \\
\hline O15357 & Phosphatidylinositol-3,4,5-trisphosphate 5-phosphatase 2 & INPPL1 \\
\hline P05412 & Transcription factor AP-1 & JUN \\
\hline Q12809 & Potassium voltage-gated channel subfamily $\mathrm{H}$ member 2 & $\mathrm{KCNH} 2$ \\
\hline Q12791 & Calcium-activated potassium channel subunit alpha 1 & KCNMA1 \\
\hline O75164 & Lysine-specific demethylase $4 \mathrm{~A}$ & KDM4A \\
\hline P35968 & Vascular endothelial growth factor receptor 2 & KDR \\
\hline Q99732 & Lipopolysaccharide-induced tumor necrosis factor-alpha factor & LITAF \\
\hline P09960 & Leukotriene A-4 hydrolase & LTA4H \\
\hline P21397 & Amine oxidase [flavin-containing] A & MAOA \\
\hline P27338 & Amine oxidase [flavin-containing] B & MAOB \\
\hline
\end{tabular}


TABLE 2: Continued.

\begin{tabular}{|c|c|c|}
\hline UniProt ID & Target & Gene name \\
\hline P11137 & Microtubule-associated protein 2 & MAP2 \\
\hline Q16539 & Mitogen-activated protein kinase 14 & MAPK14 \\
\hline P45983 & Mitogen-activated protein kinase 8 & MAPK8 \\
\hline Q13387 & C-Jun-amino-terminal kinase-interacting protein 2 & MAPK8IP2 \\
\hline Q07820 & Induced myeloid leukemia cell differentiation protein Mcl-1 & MCL1 \\
\hline P14174 & L-Dopachrome tautomerase & MIF \\
\hline P03956 & Interstitial collagenase & MMP1 \\
\hline P09238 & Stromelysin-2 & MMP10 \\
\hline P08253 & $72 \mathrm{kDa}$ type IV collagenase & MMP2 \\
\hline P08254 & Stromelysin-1 & MMP3 \\
\hline P14780 & Matrix metalloproteinase- 9 & MMP9 \\
\hline P42345 & Serine/threonine-protein kinase mTOR & MTOR \\
\hline P14598 & Neutrophil cytosol factor 1 & NCF1 \\
\hline Q15788 & Nuclear receptor coactivator 1 & NCOA1 \\
\hline Q15596 & Nuclear receptor coactivator 2 & NCOA2 \\
\hline Q9GZQ4 & Neuromedin- $\mathrm{U}$ receptor 2 & NMUR2 \\
\hline P35228 & Nitric oxide synthase, inducible & NOS2 \\
\hline P29474 & Nitric oxide synthase, endothelial & NOS3 \\
\hline P15559 & $\mathrm{NAD}(\mathrm{P}) \mathrm{H}$ dehydrogenase [quinone] 1 & NQO1 \\
\hline P04150 & Glucocorticoid receptor & $\mathrm{NR} 3 \mathrm{C} 1$ \\
\hline P08235 & Mineralocorticoid receptor & NR3C2 \\
\hline P01111 & GTPase NRas & NRAS \\
\hline P78380 & Oxidized low-density lipoprotein receptor 1 & OLR1 \\
\hline P35372 & Mu-type opioid receptor & OPRM1 \\
\hline P07237 & Protein disulfide-isomerase & $\mathrm{P} 4 \mathrm{HB}$ \\
\hline Q14432 & CGMP-inhibited $3^{\prime}, 5^{\prime}$-cyclic phosphodiesterase A & PDE3A \\
\hline P16284 & Platelet endothelial cell adhesion molecule & PECAM1 \\
\hline P06401 & Progesterone receptor & PGR \\
\hline P42336 & Phosphatidylinositol 4,5-bisphosphate 3-kinase catalytic subunit alpha isoform & PIK3CA \\
\hline P48736 & Phosphatidylinositol-4,5-bisphosphate 3-kinase catalytic subunit, gamma isoform & PIK3CG \\
\hline P11309 & Proto-oncogene serine/threonine-protein kinase Pim-1 & PIM1 \\
\hline P61925 & cAMP-dependent protein kinase inhibitor alpha & PKIA \\
\hline P00749 & Urokinase-type plasminogen activator & PLAU \\
\hline P19174 & 1-Phosphatidylinositol 4,5-bisphosphate phosphodiesterase gamma-1 & PLCG1 \\
\hline P09884 & DNA polymerase alpha catalytic subunit & POLA1 \\
\hline P06746 & DNA polymerase beta & POLB \\
\hline P54098 & DNA polymerase catalytic subunit & POLG \\
\hline P27169 & Serum paraoxonase/arylesterase 1 & PON1 \\
\hline Q03181 & Peroxisome proliferator activated receptor delta & PPARD \\
\hline P37231 & Peroxisome proliferator activated receptor gamma & PPARG \\
\hline P17612 & mRNA of PKA catalytic subunit C-alpha & PRKACA \\
\hline P17252 & Protein kinase $\mathrm{C}$ alpha type & PRKCA \\
\hline P05129 & Protein kinase $\mathrm{C}$ gamma type & PRKCG \\
\hline P07477 & Trypsin-1 & PRSS1 \\
\hline P43115 & Prostaglandin E2 receptor EP3 subtype & PTGER3 \\
\hline O14684 & Prostaglandin E synthase & PTGES \\
\hline P23219 & Prostaglandin G/H synthase 1 & PTGS1 \\
\hline P35354 & Prostaglandin G/H synthase 2 & PTGS2 \\
\hline P18031 & Protein-tyrosine phosphatase $1 \mathrm{~B}$ & PTPN1 \\
\hline P17706 & T-cell protein-tyrosine phosphatase & PTPN2 \\
\hline P29350 & Hematopoietic cell protein-tyrosine phosphatase & PTPN6 \\
\hline P11217 & Glycogen phosphorylase, muscle form & PYGM \\
\hline
\end{tabular}


TABLE 2: Continued.

\begin{tabular}{|c|c|c|}
\hline UniProt ID & Target & Gene name \\
\hline Q04206 & Transcription factor p65 & RELA \\
\hline P19793 & Retinoic acid receptor RXR-alpha & RXRA \\
\hline Q14524 & Sodium channel protein type 5 subunit alpha & SCN5A \\
\hline P16581 & E-selectin & SELE \\
\hline Q9HAS3 & Solute carrier family 28 member 3 & SLC28A3 \\
\hline O43826 & Glucose-6-phosphate translocase & SLC37A4 \\
\hline P13866 & Sodium/glucose cotransporter 1 & SLC5A1 \\
\hline P31639 & Sodium/glucose cotransporter 2 & SLC5A2 \\
\hline Q9NY91 & Low affinity sodium-glucose cotransporter & SLC5A4 \\
\hline P23975 & Sodium-dependent noradrenaline transporter & SLC6A2 \\
\hline Q01959 & Sodium-dependent dopamine transporter & SLC6A3 \\
\hline P31645 & Sodium-dependent serotonin transporter & SLC6A4 \\
\hline Q9Y6L6 & Solute carrier organic anion transporter family member 1B1 & SLCO1B1 \\
\hline P40763 & Signal transducer and activator of transcription 3 & STAT3 \\
\hline P59538 & Taste receptor type 2 member 31 & TAS2R31 \\
\hline P01137 & Transforming growth factor beta- 1 & TGFB1 \\
\hline P01375 & Tumor necrosis factor & TNF \\
\hline P11388 & DNA topoisomerase II alpha & TOP2A \\
\hline P04637 & Cellular tumor antigen p53 & TP53 \\
\hline $\mathrm{P} 17752$ & Tryptophan 5-hydroxylase 1 & TPH1 \\
\hline P14679 & Tyrosinase & TYR \\
\hline P17643 & 5,6-dihydroxyindole-2-carboxylic acid oxidase & TYRP1 \\
\hline P15692 & Vascular endothelial growth factor A & VEGFA \\
\hline P47989 & Xanthine dehydrogenase/oxidase & $\mathrm{XDH}$ \\
\hline
\end{tabular}

(STAT3) are related to both the "positive regulation and negative regulation of cell proliferation."

Xanthine dehydrogenase/oxidase (XDH), 5,6-dihydroxyindole-2-carboxylic acid oxidase (TYRP1), prostaglandin G/H synthase 2 (PTGS2), neutrophil cytosol factor 1 (NCF1), lanosterol 14-alpha demethylase (CYP51A1), amine oxidase [flavin-containing] A (MAOA), dual oxidase 2 (DUOX2), and others are associated with "oxidation-reduction process."

Bcl-2-like protein 1 (BCL2L1), interleukin-6 (IL6), mitogen-activated protein kinase 8 (MAPK8), and cellular tumor antigen p53 (TP53) are associated with both the "positive regulation and negative regulation of apoptotic process."

To summarize, it is likely that the therapeutic effect of PR in Crohn's disease is due to its anti-inflammatory and repair process and immune system enhancing effects.

3.4. Network Construction and Analysis. To visualize more conveniently the multitargeted effects of PR, network analysis was used to investigate its actions within the context of the whole human genome $[52,53]$. As shown in Figure 3, constructed (A) C-T and (B) T-P network demonstrated multicompound and multitargeted effects and relations between various pathways and targets. Circular nodes represent compounds and targets in the C-T network and triangles and circular nodes show pathways and compounds in the T-P network. In both networks, node size was regulated by degree centrality and edges showed interactions between nodes.

The C-T network showed 415 interactions between the 182 targets and 32 active compounds of PR. Ursolic acid $(\mathrm{C} 30$, degree $=55)$ had the highest number of interactions with targets, followed by beta-sitosterol $(\mathrm{C} 8$, degree $=37)$ and isorhamnetin ( $\mathrm{C} 17$, degree $=36)$, and, thus, these results demonstrated that single molecules can target multiple receptors [54]. Likewise, prostaglandin $\mathrm{G} / \mathrm{H}$ synthase 2 (PTGS2, degree $=15$ ) displayed the most affinitive connections with compounds, followed by prostaglandin $\mathrm{G} / \mathrm{H}$ synthase $1(\mathrm{PTGS1}$, degree $=13)$ and nuclear receptor coactivator $2($ NCOA2, degree $=11)$. According to betweenness centrality results, protein-tyrosine phosphatase $1 \mathrm{~B}$ (PTPN1, betweenness $=0.11$ ) was second highest followed by PTGS2 (betweenness $=0.12) .28(88 \%)$ Of the 32 active compounds were connected with more than two targets and $86(47 \%)$ of the 182 targets interact with more than one compound. This network analysis results clearly demonstrated the multitargeting natures of herbal compounds; besides it showed that ursolic acid (C30) is the most essential compound in PR.

In addition, 40 pathways related to Crohn's disease were extracted to construct the T-P network. According to degree centrality, "pathways in cancer" (degree $=49$ ) had the highest number of connections with the targets, followed by the "PI3K-Akt signaling pathway" (degree = 34 ) and "hepatitis B" (degree = 33). In the same manner, phosphatidylinositol 4,5-bisphosphate 3-kinase catalytic subunit alpha isoform (PIK3CA, degree = 33), phosphatidylinositol 4,5-bisphosphate 3-kinase catalytic subunit gamma isoform (PIK3CG, degree $=33$ ), and nuclear factor NF$\kappa \mathrm{B}$ p65 subunit (RELA, degree $=25$ ) demonstrate higher affinitive connections with pathways. Betweenness centrality and degree centrality results were similar; there was only little difference. "Pathways in cancer" (betweenness = 0.19) had the highest betweenness among the targets, which concurred with degree centrality, and this was followed by "neuroactive 


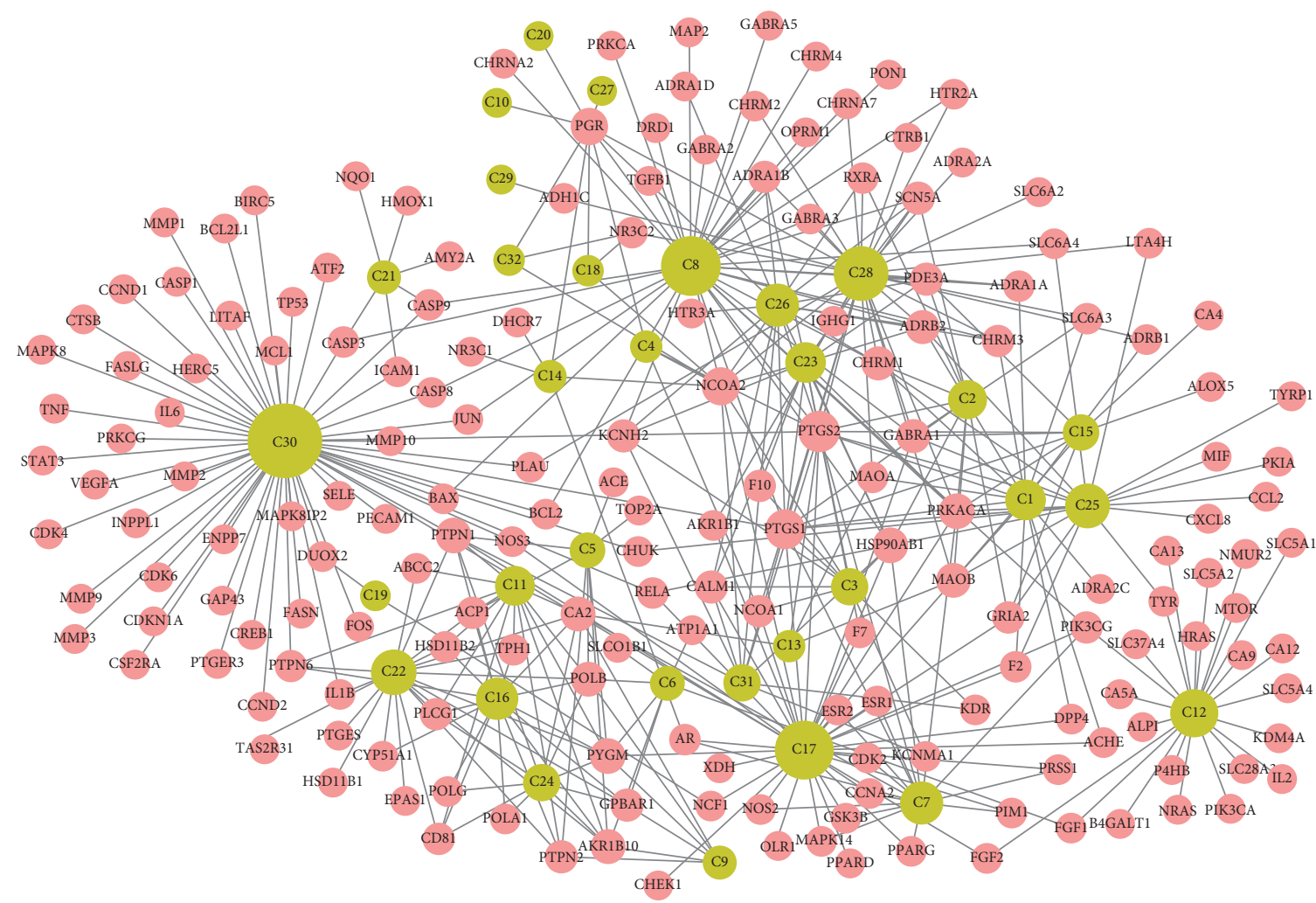

Compound

Target

(a)

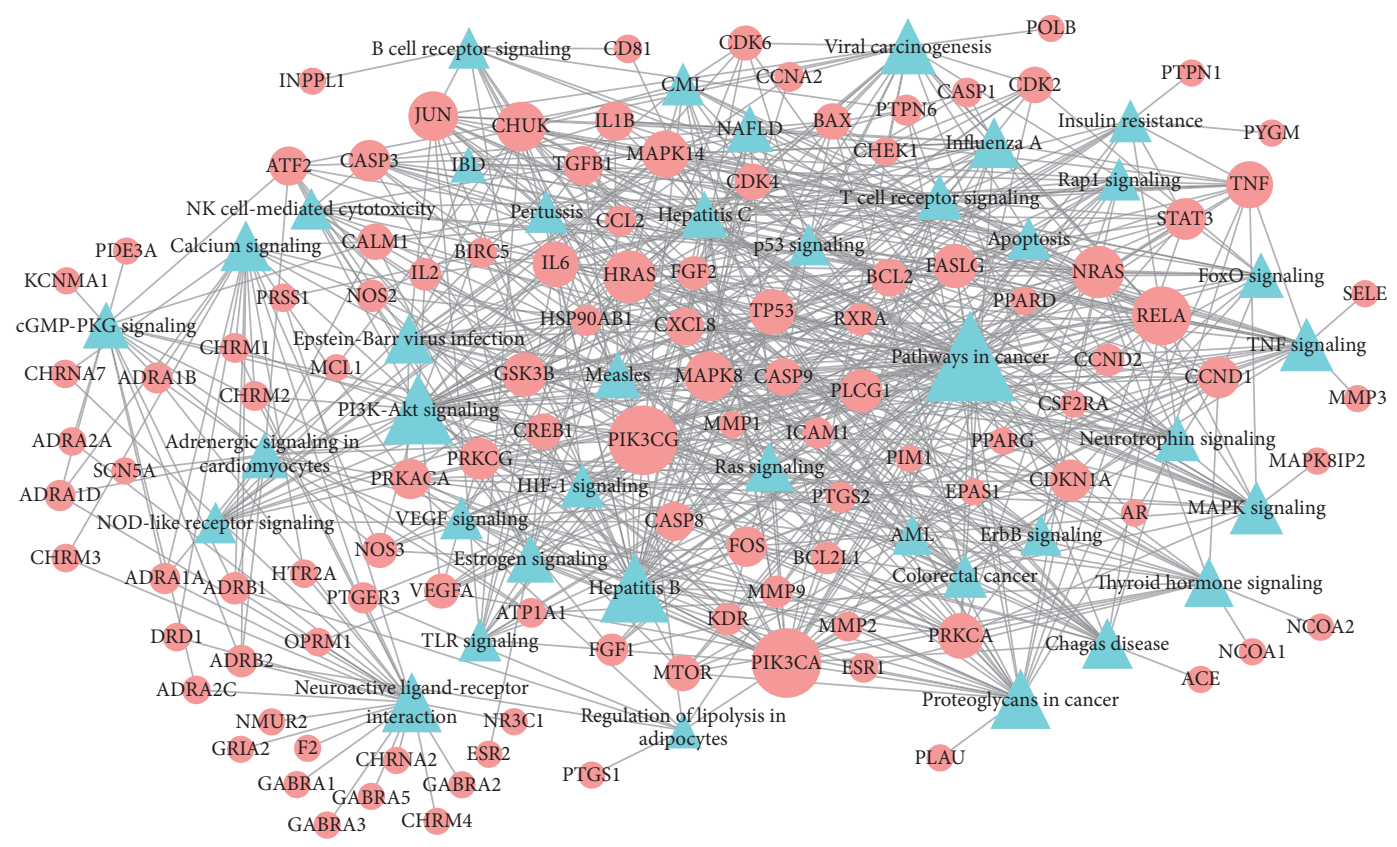

$\triangle$ Pathway

Target

(b)

FIGURE 3: C-T network and T-P network: (a) is a compound-target (C-T) network, and nodes represent compounds and targets; and (b) shows a target-pathway (T-P) network, and circular nodes represent compounds and triangles pathways. Node size is related to the degree and edges demonstrate interactions between nodes. 


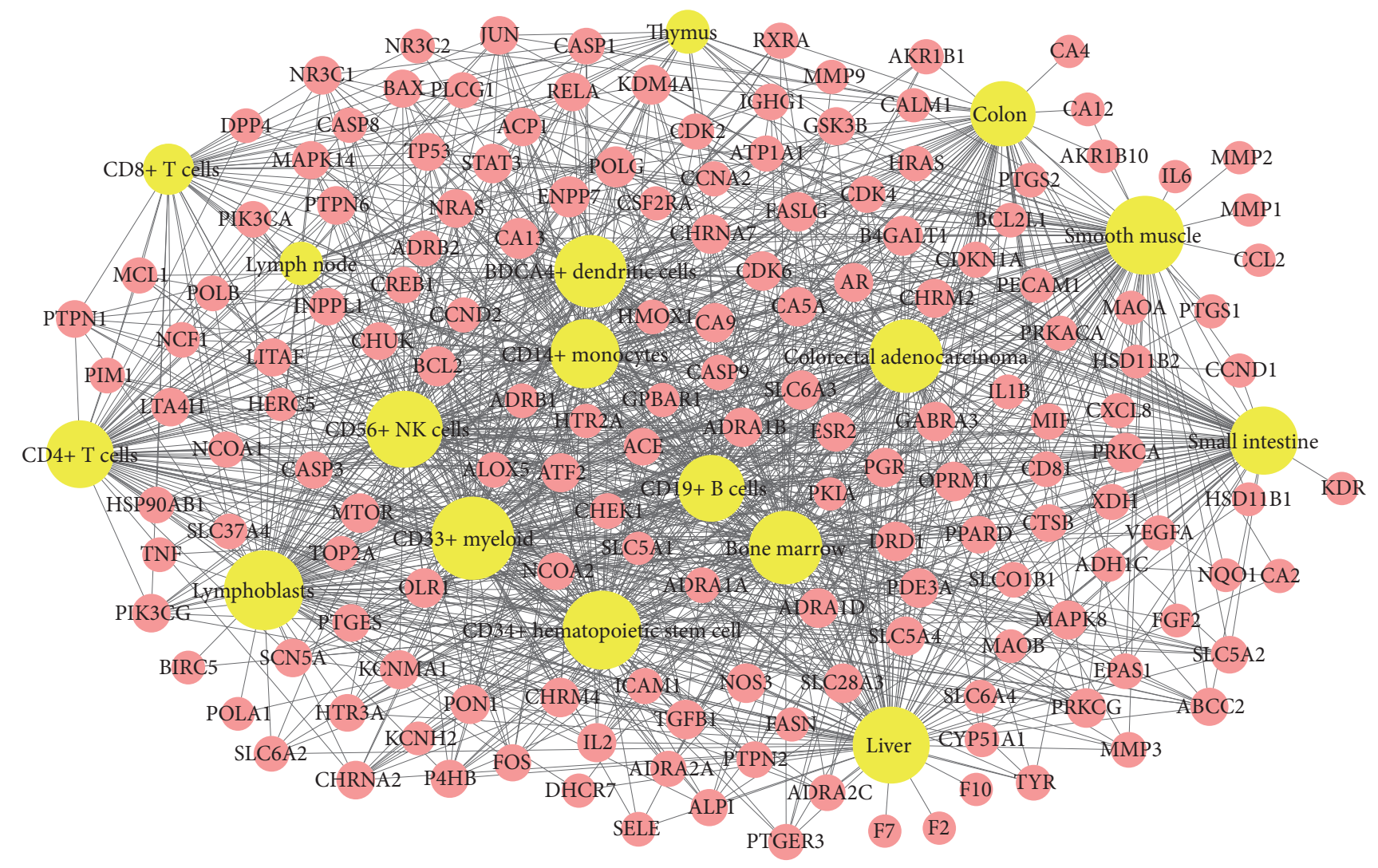

Target

Location

Figure 4: Target organ location network: the tissue-specific patterns of the mRNA expressions of targets in organs related to the immune system, colon, and small intestine. Nodes represent targets and organ locations. Node size is relative to the degree. Gene expression data was based on gene expression microarrays analysis results in BioGPS.

ligand-receptor interaction" (betweenness $=0.15$ ) and "PI3KAkt signaling pathway" (betweenness $=0.10$ ). Regarding highest betweenness targets, PIK3CA (betweenness $=0.10$ ), PIK3CG (betweenness $=0.10$ ), and prostaglandin E2 receptor EP3 subtype (PTGER3, betweenness $=0.04$ ) showed most affinitive connections with pathways.

3.5. Target Organ Location Network. The tissue mRNA expression profiles of target genes at the organ level were investigated to identify effects of PR on Crohn's disease. No mRNA expression information of three of genes, muscarinic acetylcholine receptor M1 (CHRM1), G-protein coupled receptor TGR-1 (NMUR2), and taste receptor type 2 member 31 (TAS2R31), was found in the BioGPS. In total, the mRNA expression profiles of 179 of 182 genes were analyzed (Supplementary Table S2). 158 Of the genes displayed above average mRNA expressions in 17 relevant organ tissues, namely, in BDCA4+ dendritic cells, bone marrow, CD14+ monocytes, CD19+ B cells, CD33+ myeloid cells, CD34+ hematopoietic stem cells, CD4+ T cells, CD56+ NK cells, CD8+ T cells, colon, colorectal adenocarcinoma, liver, lymph nodes, lymphoblasts, small intestine, smooth muscle, and thymus. In addition, these 17 organ tissues, retina, prefrontal cortex, pineal, amygdala, cardiac myocyte, heart, whole blood, and other tissues, were also associated with relatively high mRNA expressions. Networks of the tissue mRNA expressions of 158 target genes and PR compounds are shown in Figure 4, nodes represent organs and genes, and node sizes indicate the number of interactions between nodes.

In detail, among 84 organ tissues, CD33+ myeloid showed the most overexpressed mRNA expression, 104 genes of 158 target genes were overexpressed in CD33+ myeloid, followed by 97 genes in lymphoblasts, 95 in each of smooth muscle and CD34+ hematopoietic stem cells, 91 genes in liver and CD56+ NK cell, 84 in bone marrow and colorectal adenocarcinoma, 82 in BDCA4+ dendritic cells, 75 in CD14+ monocytes, 73 in small intestine, 72 in CD4+ T cells, 70 in CD19+ B cells, 67 in colon, 38 in CD8+ T cells, 23 in thymus, and 22 in lymph nodes. It is evident that most genes were overexpressed in several organs at the same time.

Additionally, intestinal alkaline sphingomyelinase (ENPP7), DNA polymerase catalytic subunit (POLG), and carbonic anhydrase 13 (CA13) recorded beyond average mRNA expressions in all 17 organs. Furthermore, more than 146 (92\%) of 158 target genes were overexpressed in two or more organ tissues, suggesting that these organs and 
TABLE 3: Highly expressed targets in Crohn's disease.

\begin{tabular}{|c|c|c|}
\hline UniProt ID & Target & Gene name \\
\hline Q92887 & Canalicular multispecific organic anion transporter 1 & $\mathrm{ABCC} 2$ \\
\hline O60218 & Aldo-keto reductase family 1 member B10 & AKR1B10 \\
\hline P09917 & Arachidonate 5-lipoxygenase & ALOX5 \\
\hline P62158 & Calmodulin & CALM1 \\
\hline Q00534 & Cell division protein kinase 6 & CDK6 \\
\hline P10145 & Interleukin-8 & CXCL8 \\
\hline Q99814 & Endothelial PAS domain-containing protein 1 & EPAS1 \\
\hline P01100 & Proto-oncogene c-Fos & FOS \\
\hline P47869 & Gamma-aminobutyric-acid receptor alpha-2 subunit & GABRA2 \\
\hline P49841 & Glycogen synthase kinase- 3 beta & GSK3B \\
\hline P09601 & Heme oxygenase 1 & HMOX1 \\
\hline P05362 & Intercellular adhesion molecule 1 & ICAM1 \\
\hline P01584 & Interleukin-1 beta & IL1B \\
\hline P05231 & Interleukin-6 & IL6 \\
\hline P03956 & Interstitial collagenase & MMP1 \\
\hline Q15788 & Nuclear receptor coactivator 1 & NCOA1 \\
\hline P35228 & Nitric oxide synthase, inducible & NOS2 \\
\hline P01111 & GTPase NRas & NRAS \\
\hline P11309 & Proto-oncogene serine/threonine-protein kinase Pim-1 & PIM1 \\
\hline P61925 & cAMP-dependent protein kinase inhibitor alpha & PKIA \\
\hline P00749 & Urokinase-type plasminogen activator & PLAU \\
\hline P35354 & Prostaglandin G/H synthase 2 & PTGS2 \\
\hline P40763 & Signal transducer and activator of transcription 3 & STAT3 \\
\hline P17752 & Tryptophan 5-hydroxylase 1 & TPH1 \\
\hline
\end{tabular}

compounds in PR are closely related. Furthermore, because the above 17 organs are highly related to immunity, our study results indicate that the therapeutic effects of PR on Crohn's disease are due to its targeting and activating the immune system.

The other 21 target genes, such as acetylcholinesterase (ACHE), pancreatic alpha-amylase (AMY2A), and muscarinic acetylcholine receptor M3 (CHRM3), did not show above average mRNA expression in the 17 organs.

3.6. GEO2R Analysis. Comparison data between normal tissue and Crohn's disease patients' mRNA expression pattern from Gene Expression Omnibus (GEO) was collected. We employed GEOquery and limma R packages of GEO2R tool to identify highly expressed genes in 6 datasets. Dataset accession numbers are as follows: GSE24287, GSE60083, GSE6731, GSE36807, GSE68570, and GSE72780. To sum up, 86 normal samples and 149 Crohn's disease samples were analyzed in each dataset. GEO2R presented the top 250 highly expressed genes in Crohn's disease group compared to the control group and we deleted overlaps, so, in the end, 1182 genes were sorted out.

We found out that there were 23 common genes (Table 3 ) between target genes of PR and highly expressed genes of Crohn's disease dataset from GEO.

3.7. Network Pathway. In order to investigate further the effect of PR in Crohn's disease, we performed pathway enrichment analysis (Figure 5). Using the IBD pathway provided by the KEGG pathway database, we confirmed the pathway mapping effect of PR in Crohn's disease by inputting the filtered human target genes into the pathway. The KEGG pathway was constructed according to the current knowledge of the pathogenesis IBD.

The synthesis of inflammatory cytokines, such as IL1 , IL- 6 and TNF- $\alpha$, is mediated by NF- $\kappa$ B, which is a key regulator of inflammation $[55,56]$. We found that oleanolic acid derivative (C22) targets IL-1; ursolic acid (C30) targets all of IL-1, IL-6, and TNF; isorhamnetin (C17), scoparone (C25), and ursolic acid (C30) target nuclear factor NF- $\kappa$ B p65 subunit (RELA); and scoparone (C25) and ursolic acid (C30) target $\mathrm{NF}-\kappa \mathrm{B}$ inhibitor alpha $(\mathrm{CHUK})$, which suggests that these compounds affect NF- $\kappa \mathrm{B}$ activity. Cernuoside (C12) targets IL-2. Beta-sitosterol (C8) targets transforming growth factor beta-1 (TGFB1) and transcription factor AP-1 (JUN), and ursolic acid (C30) also targets transcription factor AP1 (JUN) and signal transducer and activator of transcription 3 (STAT3). Furthermore, NF- $\kappa$ B and AP-1 in combination are highly related to the initial inflammatory response and to the development of acquired immunity [57]. Moreover, IL-6mediated STAT3 activation on mucosal T cells may has been suggested to play a role in the development of IBD [58].

\section{Discussion}

In this study, a network pharmacology method with active compounds filtration, multiple drug target prediction, gene ontology, network analysis, relevant organ location network, and pathway enrichment analysis were employed to determine the targets of PR in relation to Crohn's disease. Our 


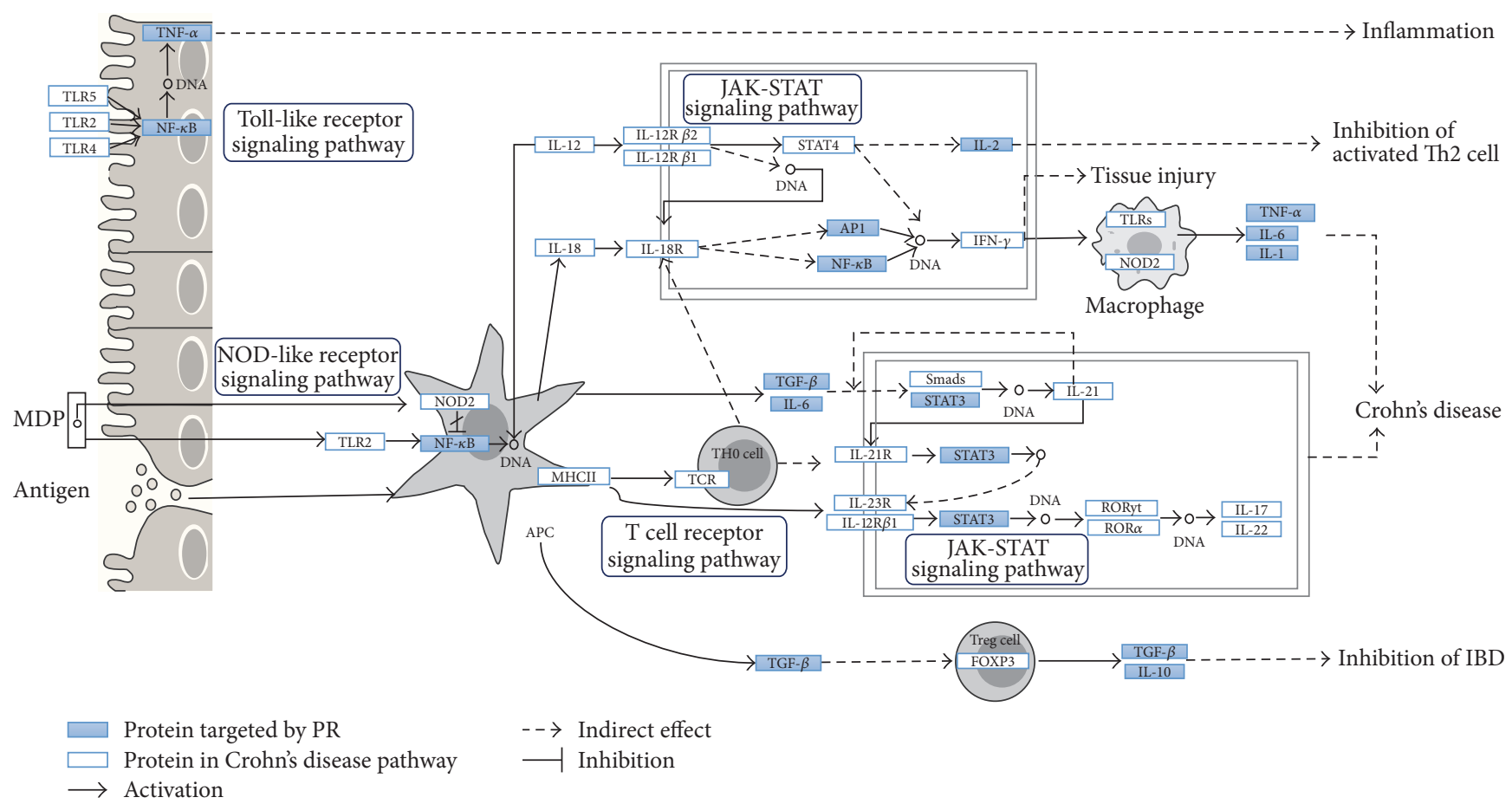

FIGURE 5: Network pathway: pathway enrichment analysis was performed. 182 filtered target genes were mapped into the Crohn's disease pathway from the Kyoto Encyclopedia of Genes and Genomes (KEGG) to confirm the possible effect pathway of Pulsatillae Radix (PR) on Crohn's disease.

study shows that PR is highly connected to the pathways, biological processes, and organs of Crohn's disease. A pharmacological approach was used to identify the actions of PR at the systems network level.

In this study, pathway mapping result showed that the target genes of PR overlap more with Crohn's disease than with ulcerative colitis. Experimental study also suggested that the markers of both diseases are different from each other $[59,60]$. The clinical symptoms of these diseases also differ; for instance, Crohn's disease affect any region of the entire gastrointestinal (GI) tract and all layers of the bowel wall, whereas ulcerative colitis affects only the mucosa and submucosa of colon [61]. Furthermore, ulcerative colitis can be cured by surgery, but Crohn's disease of any part of GI tract tends to relapse after surgery [62]. For this reason, long term management using herbal medicines might be highly recommendable treatment option for Crohn's disease, since herbal medicines have advantages for managing chronic diseases [63, 64].

In addition, IBD is usually referred to as an autoimmune disorder [65], whereas Crohn's disease does not meet the criteria of an autoimmune disorder; rather it is associated with immune deficiency or a secondary immune response to altered intestinal microbiota [65]. Furthermore, ulcerative colitis is a mucosal disease where autoimmune autoantibodies are commonly detected [66], whereas Crohn's disease is a transmural disease, in which pathological changes in gut wall are thought to result from submucosal inflammatory changes [67]. Accordingly, the areas targeted for treatment in these two diseases should be differentiated.
In the present study, we focused on the use of PR as a potential therapy for Crohn's disease. However, herb pairs and combinations are more commonly prescribed and are regarded to be more effective and safer [68]. In terms of the Gunsinjwasa theory of traditional medicine combinations, there are four different roles for each herb in the formula. First, the major component targets the main symptom. Second, the supportive component assists the effect of the major component or targets the secondary symptoms. Third, the neutralizing component allays the side effects or toxins of the major and the supportive component. Fourth, the deliver/retaining component guides the medicine to the targeting part of the body $[69,70]$. This combination principle enables not only the enhancement of synergistic medicinal effects but also potentially reduces toxicities [69]. In order to induce better effects and reduce toxicities, an extended analysis of the Pulsatillae Radix (Baekduong, PR), Phellodendri Cortex (Hwangbaek), Coptidis Rhizoma (Hwangryeon), and Citrus reticulata (Jinpi) herb combination (a widely prescribed formula, known as Baekduong decoction) should be explored in the future.

Through GO analysis, we found out that targets of PR are associated with liver diseases such as hepatitis B, hepatitis $\mathrm{C}$, and nonalcoholic fatty liver. In addition, the mRNA expression of 91 of 179 genes in liver was overexpressed according to the target organ location network result. Liver inflammation is as common extraintestinal symptom of Crohn's disease [71], and the number of liver abscesses in Crohn's disease patients is 15 to 20 times higher than that found in the general population [72]. Besides biochemical 
liver dysfunction [73] and hepatic fibrosis [74] are also frequently found in Crohn's disease, and a number of drugs used to treat IBD have been reported to be associated with liver injury [75]. Furthermore, in an experimental study using a mice model of Crohn's disease-like ileitis, it was found that TLR9 plays an important role in hepatic involvement in IBD [71]. More detailed pathways and relations between liver and Crohn's disease should be discussed in the future.

This study demonstrated that 73 and 67 of 158 targets of PR were highly expressed in small intestine and colon, respectively, results which were accordance with not only the organs commonly affected by Crohn's disease but also the properties of PR in terms of meridian tropism theory. However stronger evidence with another research design is required to support this result.

We confirmed a multicompound and multitarget interaction through the C-T network, which showed that $88 \%$ of the active compounds were connected with more than two targets and $47 \%$ of the targets interacted with more than one compound. Although it demonstrated the synergetic network of multitarget actions, we should explore more differentiated drug action based on degree centrality and how different the drug actions are when more compounds target one gene in simultaneous way compared to the case of one compound targeting one gene.

\section{Conclusion}

Previous studies indicate that most compounds in PR have anti-inflammatory, anticancer, and antioxidant effects. In the present study, we found that these compounds interact with multiple targets in a synergetic manner and that PR is highly connected to Crohn's disease related pathways, biological processes, and organs. C-T and T-P network results demonstrated complex multicompound and multitarget drug actions and the relations between targets and various pathways. Furthermore, target genes were found to be overexpressed in organs highly related to immunity. These findings suggest the anti-inflammatory effects of PR, and its enhancements of repair processes and immune system might be of therapeutic benefit in Crohn's disease.

\section{Conflicts of Interest}

The authors have no conflicts of interest to declare.

\section{Acknowledgments}

This research was supported by Basic Science Research Program through the National Research Foundation of Korea (NRF) funded by the Ministry of Education (NRF2015R1D1A1A01059994).

\section{References}

[1] D. C. Baumgart, Crohn's Disease and Ulcerative Colitis: From Epidemiology and Immunobiology to a Rational Diagnostic and Therapeutic Approach, Springer Science \& Business Media, 2012.
[2] D. C. Baumgart and W. J. Sandborn, "Crohn's disease," The Lancet, vol. 380, no. 9853, pp. 1590-1605, 2012.

[3] W. C. Tan and R. N. Allan, "Diffuse jejunoileitis of Crohn's disease," Gut, vol. 34, no. 10, pp. 1374-1378, 1993.

[4] R. Dessein, M. Chamaillard, and S. Danese, "Innate immunity in Crohn's disease: the reverse side of the medal," Journal of Clinical Gastroenterology, vol. 42, supplement 3, pp. S144-S147, 2008.

[5] D. N. Floyd, S. Langham, H. C. Séverac, and B. G. Levesque, "The economic and quality-of-life burden of crohn's disease in Europe and the United States, 2000 to 2013: a systematic review," Digestive Diseases and Sciences, vol. 60, no. 2, pp. 299-312, 2016.

[6] D. J. B. Marks, F. Z. Rahman, G. W. Sewell, and A. W. Segal, "Crohn's disease: an immune deficiency state," Clinical Reviews in Allergy \& Immunology, vol. 38, no. 1, pp. 20-31, 2010.

[7] T. Stefanelli, A. Malesci, A. Repici, S. Vetrano, and S. Danese, "New insights into inflammatory bowel disease pathophysiology: paving the way for novel therapeutic targets," Current Drug Targets, vol. 9, no. 5, pp. 413-418, 2008.

[8] B. Hayee, F. Z. Rahman, G. Sewell, A. M. Smith, and A. W. Segal, "Crohn's disease as an immunodeficiency," Expert Review of Clinical Immunology, vol. 6, no. 4, pp. 585-596, 2010.

[9] A. N. Ananthakrishnan, R. J. Xavier, and D. K. Podolsky, "Inflammatory bowel diseases: pathogenesis," Yamada's Textbook of Gastroenterology, pp. 1364-1377, 2016.

[10] S. C. Ng, Y. T. Lam, K. K. F. Tsoi, F. K. L. Chan, J. J. Y. Sung, and J. C. Y. Wu, "Systematic review: the efficacy of herbal therapy in inflammatory bowel disease," Alimentary Pharmacology and Therapeutics, vol. 38, no. 8, pp. 854-863, 2013.

[11] M. Sałaga, H. Zatorski, M. Sobczak, C. Chen, and J. Fichna, "Chinese herbal medicines in the treatment of IBD and colorectal cancer: a review," Current Treatment Options in Oncology, vol. 15, no. 3, pp. 405-420, 2014.

[12] S.-H. Kim, "Anti-inflammatory effect of Pulsatilla koreana," pp. $1-49,2008$.

[13] L. Y.-M. K. Hyo-Jin, "Pulsatilla koreana ethanol extract suppress adipocyte differentiation and adipogenesis via down-regulation of PPAR- $\gamma$ and C/EBPs," pp. 1-47, 2014.

[14] W. Li, Y. Ding, Y. N. Sun et al., "Oleanane-type triterpenoid saponins from the roots of Pulsatilla koreana and their apoptosis-inducing effects on HL-60 human promyelocytic leukemia cells," Archives of Pharmacal Research, vol. 36, no. 6, pp. 768-774, 2013.

[15] W. Li, Y. Ding, Y. N. Sun et al., "Triterpenoid saponins of pulsatilla koreana root have inhibition effects of tumor necrosis factor- $\alpha$ secretion in lipopolysaccharide-induced RAW264.7 cells," Chemical and Pharmaceutical Bulletin, vol. 61, no. 4, pp. 471-476, 2013.

[16] B. H. Park, K. H. Jung, M. K. Son et al., "Antitumor activity of Pulsatilla koreana extract in anaplastic thyroid cancer via apoptosis and anti-angiogenesis," Molecular Medicine Reports, vol. 7, no. 1, pp. 26-30, 2013.

[17] S. H. Lee, E. Lee, and Y. T. Ko, "Anti-inflammatory effects of a methanol extract from Pulsatilla koreana in lipopolysaccharideexposed rats," BMB Reports, vol. 45, no. 6, pp. 371-376, 2012.

[18] Y. Zhao, Y. Li, X. Wang, and W. J. Sun, “The experimental study of Cortex Eucommiae on meridian tropsim: the distribution study of aucubin in rat tissues," Journal of Pharmaceutical and Biomedical Analysis, vol. 46, no. 2, pp. 368-373, 2008.

[19] Y.-X. Chang, Y.-G. Sun, J. Li et al., "The experimental study of Astragalus membranaceus on meridian tropsim: The distribution study of astragaloside IV in rat tissues," Journal of 
Chromatography B: Analytical Technologies in the Biomedical and Life Sciences, vol. 911, pp. 71-75, 2012.

[20] M. Shen, S. Tian, Y. Li et al., "Drug-likeness analysis of traditional Chinese medicines: 1 . property distributions of drug-like compounds, non-drug-like compounds and natural compounds from traditional Chinese medicines," Journal of Cheminformatics, vol. 4, no. 1, article 31, 2012.

[21] X. Xu, W. Zhang, C. Huang et al., "A novel chemometric method for the prediction of human oral bioavailability," International Journal of Molecular Sciences, vol. 13, no. 6, pp. 6964-6982, 2012.

[22] I. Hubatsch, E. G. E. Ragnarsson, and P. Artursson, "Determination of drug permeability and prediction of drug absorption in Caco-2 monolayers," Nature Protocols, vol. 2, no. 9, pp. 21112119, 2007.

[23] W. Tao, X. Xu, X. Wang et al., "Network pharmacology-based prediction of the active ingredients and potential targets of Chinese herbal Radix Curcumae formula for application to cardiovascular disease," Journal of Ethnopharmacology, vol. 145, no. 1, pp. 1-10, 2013.

[24] J. Zhang, Y. Li, S.-S. Chen et al., "Systems pharmacology dissection of the anti-inflammatory mechanism for the medicinal herb Folium eriobotryae," International Journal of Molecular Sciences, vol. 16, no. 2, pp. 2913-2941, 2015.

[25] P. Willett, J. M. Barnard, and G. M. Downs, "Chemical similarity searching," Journal of Chemical Information and Computer Sciences, vol. 38, no. 6, pp. 983-996, 1998.

[26] H. Liu, J. Wang, W. Zhou, Y. Wang, and L. Yang, "Systems approaches and polypharmacology for drug discovery from herbal medicines: an example using licorice," Journal of Ethnopharmacology, vol. 146, no. 3, pp. 773-793, 2013.

[27] K. S. Pang, "Modeling of intestinal drug absorption: Roles of transporters and metabolic enzymes (for the gillette review series)," Drug Metabolism \& Disposition, vol. 31, no. 12, pp. 15071519, 2003.

[28] T. Pei, C. Zheng, C. Huang et al., "Systematic understanding the mechanisms of vitiligo pathogenesis and its treatment by Qubaibabuqi formula," Journal of Ethnopharmacology, vol. 190, pp. 272-287, 2016.

[29] H. Yu, J. Chen, X. Xu et al., "A systematic prediction of multiple drug-target interactions from chemical, genomic, and pharmacological data," PLOS ONE, vol. 7, no. 5, Article ID e37608, 2012.

[30] C. H. Wu, R. Apweiler, A. Bairoch et al., "The Universal Protein Resource (UniProt): an expanding universe of protein information," Nucleic Acids Research, vol. 34, no. Database issue, pp. D187-D191, 2006.

[31] G. Bindea, B. Mlecnik, H. Hackl et al., "ClueGO: a Cytoscape plug-in to decipher functionally grouped gene ontology and pathway annotation networks," Bioinformatics, vol. 25, no. 8, pp. 1091-1093, 2009.

[32] M. E. Smoot, K. Ono, J. Ruscheinski, P. L. Wang, and T. Ideker, "Cytoscape 2.8: new features for data integration and network visualization," Bioinformatics, vol. 27, no. 3, pp. 431-432, 2011.

[33] J.-B. Pan, S.-C. Hu, D. Shi et al., "PaGenBase: a pattern gene database for the global and dynamic understanding of gene function," PLoS ONE, vol. 8, no. 12, Article ID e80747, 2013.

[34] W. Zhang, Q. Tao, Z. Guo et al., "Systems pharmacology dissection of the integrated treatment for cardiovascular and gastrointestinal disorders by traditional chinese medicine," Scientific Reports, vol. 6, p. 32400, 2016.
[35] Z. Prevoršek, G. Gorjanc, B. Paigen, and S. Horvat, "Congenic and bioinformatics analyses resolved a major-effect Fob3b QTL on mouse Chr 15 into two closely linked loci," Mammalian Genome, vol. 21, no. 3-4, pp. 172-185, 2010.

[36] K. Senthil Kumar and R. Kumaresan, "A comparative study on the antioxidant properties of bractein and cernuoside by the DFT method," Monatshefte fur Chemie, vol. 144, no. 10, pp. 15131524, 2013.

[37] T. Guo, Y.-X. Deng, H. Xie et al., "Antinociceptive and antiinflammatory activities of ethyl acetate fraction from Zanthoxylum armatum in mice," Fitoterapia, vol. 82, no. 3, pp. 347-351, 2011.

[38] D. Kmiecik, J. Korczak, M. Rudzińska, J. Kobus-Cisowska, A. Gramza-Michałowska, and M. Hęś, " $\beta$-Sitosterol and campesterol stabilisation by natural and synthetic antioxidants during heating," Food Chemistry, vol. 128, no. 4, pp. 937-942, 2011.

[39] Y. H. Choi and G. H. Yan, "Anti-allergic effects of scoparone on mast cell-mediated allergy model," Phytomedicine, vol. 16, no. 12, pp. 1089-1094, 2009.

[40] K. S. Kumar and R. Kumaresan, "A quantum chemical study on the antioxidant properties of aureusidin and bracteatin," International Journal of Quantum Chemistry, vol. 111, no. 15, pp. 4483-4496, 2011.

[41] M. Roussaki, A. Gaitanarou, P. C. Diamanti et al., "Encapsulation of the natural antioxidant aureusidin in biodegradable PLA nanoparticles," Polymer Degradation and Stability, vol. 108, pp. 182-187, 2014.

[42] Q. Yanping, "Effects of velvet for the tumor and immune function in tumor-bearing mice," Journal of Heilongjiang Bayi Agricultural University, vol. 1, p. 17, 2012.

[43] F. Dan and Z. C. Bin, "The anti-tumor effect of the extract from Radix Pulsatillae," Chinese Journal of Hospital Pharmacy, vol. 9, p. 009, 2003.

[44] S. F. Vasilevsky, A. I. Govdi, I. V. Sorokina et al., "Rapid access to new bioconjugates of betulonic acid via click chemistry," Bioorganic and Medicinal Chemistry Letters, vol. 21, no. 1, pp. 62-65, 2011.

[45] Y. Lee, J.-C. Jung, Z. Ali, I. A. Khan, and S. Oh, "Antiinflammatory effect of triterpene saponins isolated from blue cohosh (caulophyllum thalictroides)," Evidence-based Complementary and Alternative Medicine, vol. 2012, Article ID 798192, 8 pages, 2012.

[46] N. Chen, Y.-B. Ji, D.-X. Song, C.-R. Xu, H. Song, and J. Li, "Effects of Dauricine concentration in asiatic moonseed by different extraction solvents and methods," Applied Mechanics and Materials, vol. 411-414, pp. 3162-3165, 2013.

[47] L. Ma, H. Chen, P. Dong, and X. Lu, "Anti-inflammatory and anticancer activities of extracts and compounds from the mushroom Inonotus obliquus," Food Chemistry, vol. 139, no. 1-4, pp. 503-508, 2013.

[48] C. Boesch-Saadatmandi, A. Loboda, A. E. Wagner et al., "Effect of quercetin and its metabolites isorhamnetin and quercetin-3glucuronide on inflammatory gene expression: role of miR-155," Journal of Nutritional Biochemistry, vol. 22, no. 3, pp. 293-299, 2011.

[49] J. Liu, "Oleanolic acid and ursolic acid: research perspectives," Journal of Ethnopharmacology, vol. 100, no. 1-2, pp. 92-94, 2005.

[50] S.-J. Tsai and M.-C. Yin, "Antioxidative and anti-inflammatory protection of oleanolic acid and ursolic acid in PC12 cells," Journal of Food Science, vol. 73, no. 7, pp. H174-H178, 2008. 
[51] J. Liu, T. Pei, J. Mu et al., "Systems pharmacology uncovers the multiple mechanisms of Xijiao Dihuang decoction for the treatment of viral hemorrhagic fever," Evidence-Based Complementary and Alternative Medicine, vol. 2016, Article ID 9025036, 17 pages, 2016.

[52] S. I. Berger and R. Iyengar, "Network analyses in systems pharmacology," Bioinformatics, vol. 25, no. 19, pp. 2466-2472, 2009.

[53] P. Li, L.-W. Qi, E.-H. Liu, J.-L. Zhou, and X.-D. Wen, “Analysis of Chinese herbal medicines with holistic approaches and integrated evaluation models," TrAC-Trends in Analytical Chemistry, vol. 27, no. 1, pp. 66-77, 2008.

[54] L. M. Espinoza-Fonseca, "The benefits of the multi-target approach in drug design and discovery," Bioorganic and Medicinal Chemistry, vol. 14, no. 4, pp. 896-897, 2006.

[55] P. P. Tak and G. S. Firestein, "NF- $\kappa$ B: a key role in inflammatory diseases," Journal of Clinical Investigation, vol. 107, no. 1, pp. 7-11, 2001.

[56] W. Xiao, D. R. Hodge, L. Wang, X. Yang, X. Zhang, and W. L. Farrar, "NF- $\kappa$ B activates IL-6 expression through cooperation with c-Jun and IL6-AP1 site, but is independent of its IL6-NFא B regulatory site in autocrine human multiple myeloma cells," Cancer Biology \& Therapy, vol. 3, no. 10, pp. 1007-1017, 2004.

[57] C. K. Glass and K. Saijo, "Nuclear receptor transrepression pathways that regulate inflammation in macrophages and $\mathrm{T}$ cells," Nature Reviews Immunology, vol. 10, no. 5, pp. 365-376, 2010.

[58] K. Mitsuyama, S. Matsumoto, J. Masuda et al., "Therapeutic strategies for targeting the IL-6/STAT3 cytokine signaling pathway in inflammatory bowel disease," Anticancer Research, vol. 27, no. 6A, pp. 3749-3756, 2007.

[59] K. Yamazaki, J. Umeno, A. Takahashi et al., "A genome-wide association study identifies 2 susceptibility loci for Crohn's disease in a Japanese population," Gastroenterology, vol. 144, no. 4, pp. 781-788, 2013.

[60] F. Costa, M. G. Mumolo, L. Ceccarelli et al., "Calprotectin is a stronger predictive marker of relapse in ulcerative colitis than in Crohn's disease," Gut, vol. 54, no. 3, pp. 364-368, 2005.

[61] M. E. Ament, "Inflammatory disease of the colon: ulcerative colitis and Crohn's colitis," The Journal of Pediatrics, vol. 86, no. 3, pp. 322-334, 1975.

[62] I. Kristo, A. Stift, M. Bergmann, and S. Riss, "Surgical recurrence in Crohn's disease: are we getting better?" World Journal of Gastroenterology, vol. 21, no. 20, pp. 6097-6100, 2015.

[63] C. Elder, C. Ritenbaugh, M. Aickin et al., "Reductions in pain medication use associated with traditional Chinese medicine for chronic pain," Issues, vol. 16, pp. 18-23, 2016.

[64] M. Tan, M. Win, and S. A. Khan, "The use of complementary and alternative medicine in chronic pain patients in Singapore: a single-centre study," Annals of the Academy of Medicine, Singapore, vol. 42, no. 3, pp. 133-137, 2013.

[65] M. A. Behr, M. Divangahi, and J.-D. Lalande, "What's in a name? The (mis)labelling of Crohn's as an autoimmune disease," The Lancet, vol. 376, no. 9736, pp. 202-203, 2010.

[66] K. M. Das and L. Biancone, "Is IBD an autoimmune disorder?" Inflammatory Bowel Diseases, vol. 14, no. S2, pp. S97-S101, 2008.

[67] B. B. Crohn, L. Ginzburg, and G. D. Oppenheimer, "Regional ileitis: a pathologic and clinical entity," Journal of the American Medical Association, vol. 99, no. 16, pp. 1323-1329, 1932.
[68] A. Riaz, R. A. Khan, S. Ahmed, and S. Afroz, "Assessment of acute toxicity and reproductive capability of a herbal combination," Pakistan Journal of Pharmaceutical Sciences, vol. 23, no. 3, pp. 291-294, 2010.

[69] H. U. Kim, J. Y. Ryu, J. O. Lee, and S. Y. Lee, "A systems approach to traditional oriental medicine," Nature Biotechnology, vol. 33, no. 3, pp. 264-268, 2016.

[70] H.-Y. Hsieh, P.-H. Chiu, and S.-C. Wang, "Epigenetics in traditional chinese pharmacy: a bioinformatic study at pharmacopoeia scale," Evidence-based Complementary and Alternative Medicine, vol. 2011, Article ID 816714, 10 pages, 2011.

[71] S. Omenetti, M. Brogi, R. Garg et al., "Essential role for Toll-like receptor 9 in the pathogenesis of liver inflammation in a murine model of Crohns disease-like ileitis (P3147)," The Journal of Immunology, vol. 190, no. 1 supplement, pp. 35-43, 2013.

[72] S. H. Mir-Madjlessi, M. C. McHenry, and R. G. Farmer, "Liver abscess in Crohn's disease. Report of four cases and review of the literature," Gastroenterology, vol. 91, no. 4, pp. 987-993, 1986.

[73] A. D. Perrett, G. Higgins, H. H. Johnston et al., "The liver in Crohn's disease," Gastroenterology, vol. 40, no. 158, pp. 187-209, 1971.

[74] M. N. Eade, W. T. Cooke, and I. A. Williams, "Liver disease in crohn's disease: a study of 100 consecutive patients," Scandinavian Journal of Gastroenterology, vol. 6, no. 3, pp. 199-204, 1971.

[75] J. Carvalheiro, S. Mendes, and C. Sofia, "Infliximab induced liver injury in Crohn's disease: a challenging diagnosis," Journal of Crohn's and Colitis, vol. 8, no. 5, pp. 436-437, 2014. 


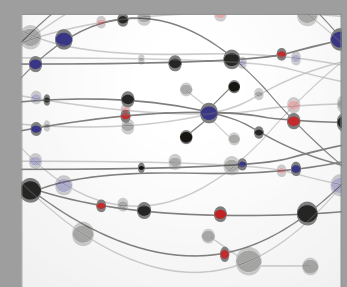

The Scientific World Journal
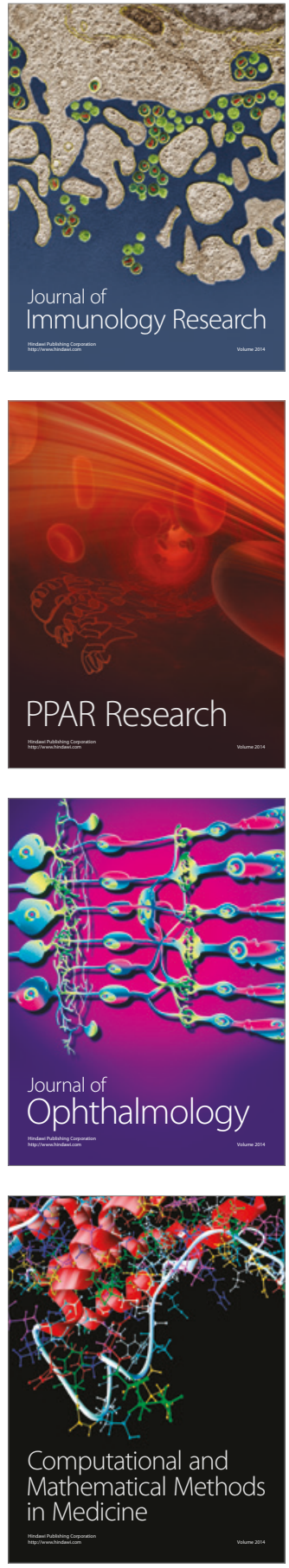

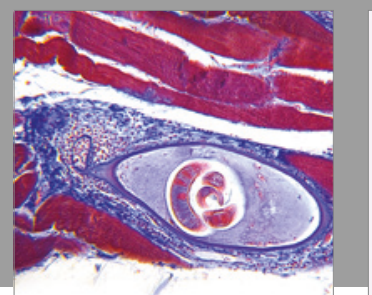

Gastroenterology Research and Practice
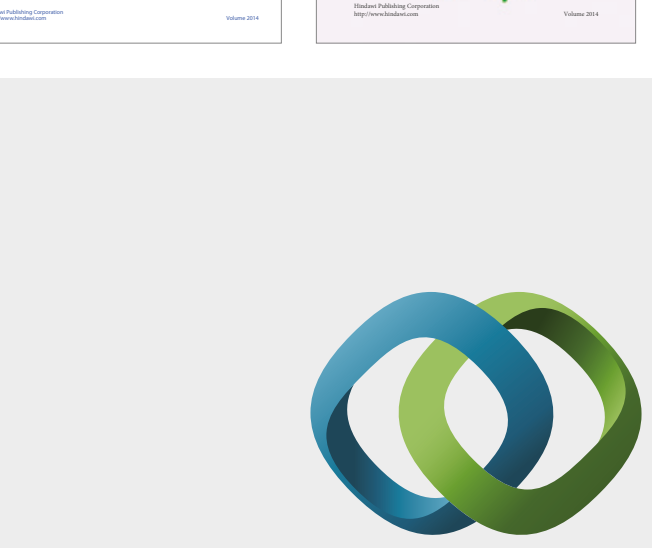

\section{Hindawi}

Submit your manuscripts at

https://www.hindawi.com
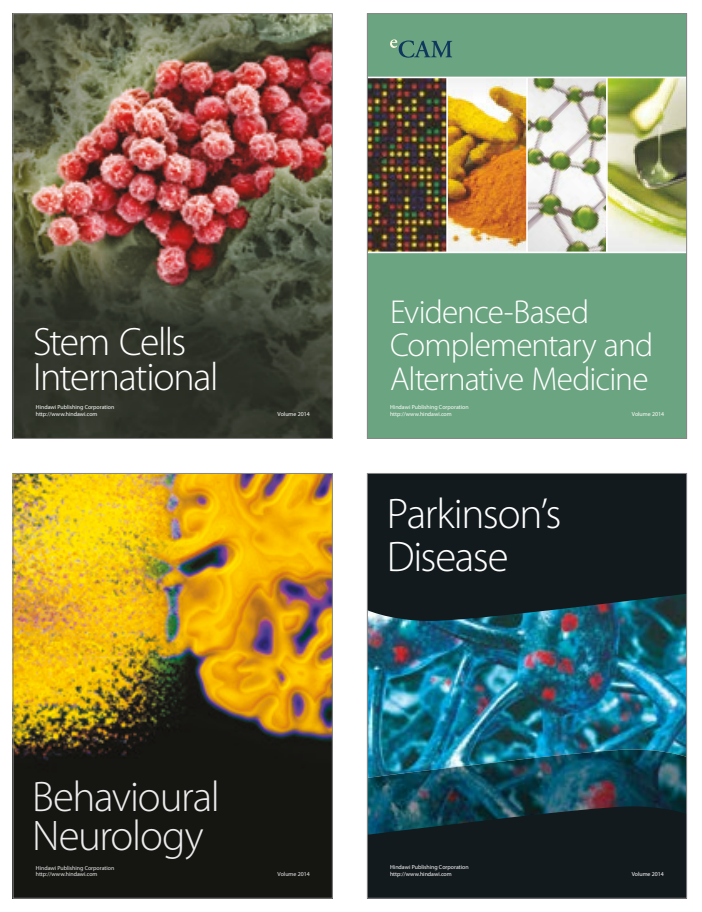
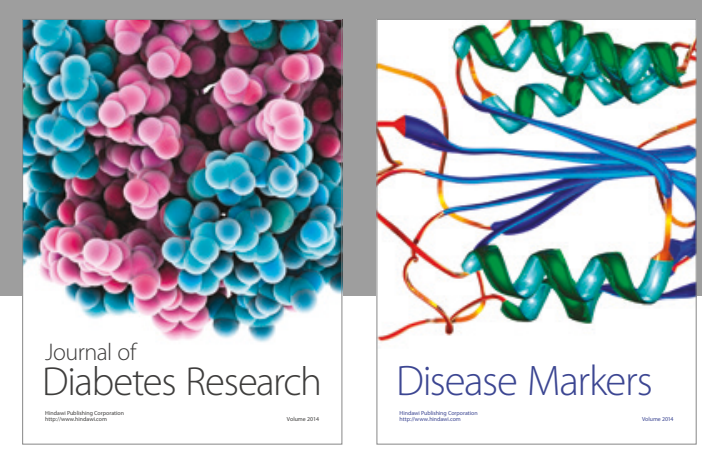

Disease Markers
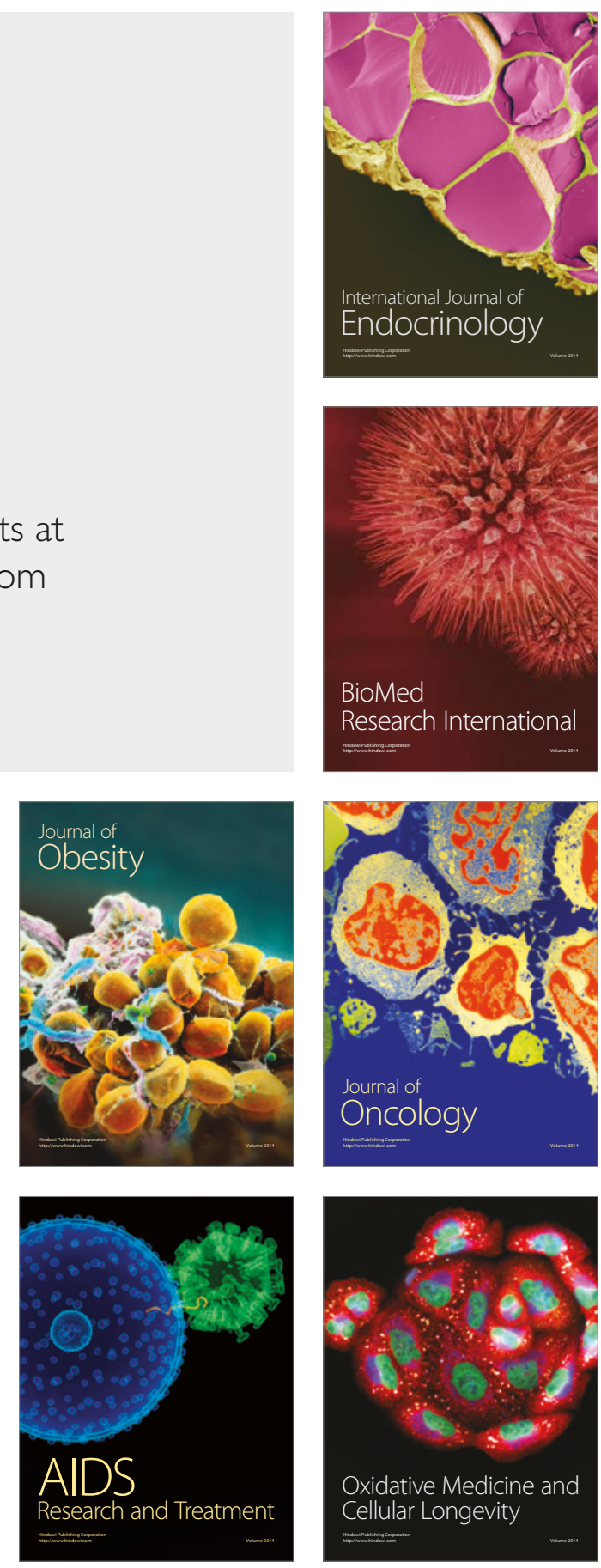